\title{
Combined Experimental-Numerical Analysis of Transient Phenomena in a Photoelectrochemical Water Splitting Cell
}

\author{
Mikael Dumortier, ${ }^{\dagger} \S$ Tom Bosserez, ${ }^{\ddagger}, \S$ Jan Rongé, ${ }^{\dagger}$ Johan A. Martens, ${ }^{\ddagger}$ and Sophia Haussener* ${ }^{* \dagger}$ \\ ${ }^{\dagger}$ Laboratory of Renewable Energy Science and Engineering, EPFL, Station 9, 1015 Lausanne, Switzerland \\ ${ }^{\ddagger}$ Centre for Surface Chemistry and Catalysis, KU Leuven, Celestijnenlaan 200F, Leuven B-3001, Belgium
}

Supporting Information

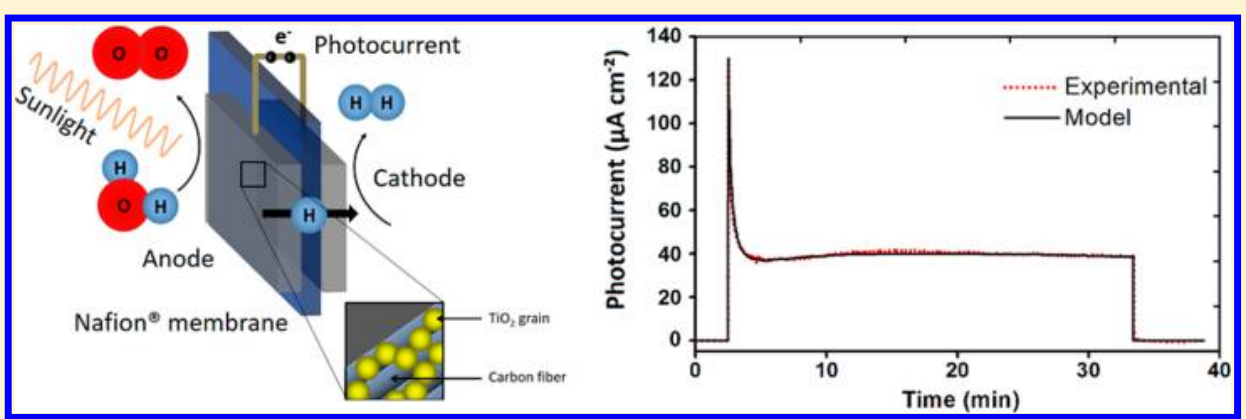

ABSTRACT: A combined experimental-numerical approach was used to study transient phenomena occurring in a photoelectrochemical cell using a membrane-separated porous $\mathrm{TiO}_{2}$-based photoanode and a dark Pt-based cathode. The effects of three parameters ( $\mathrm{pH}$ in the anodic compartment, operating cell temperature, and cathode compartment preconditioning with hydrogen) on the photocurrent was systematically investigated using design of experiments and analysis of variance. A theoretical model was developed able to accurately reproduce and predict the measurements. The model indicated that the electrochemical reaction uses two parallel pathways on the anodic interface. The first pathway represented the rapid charging of surface states and the subsequent formation of acidic titanol groups at the $\mathrm{TiO}_{2} / \mathrm{H}_{2} \mathrm{O}$ interface which, upon illumination, caused an anodic overshoot at a short time scale. These states recombined with the formed $\mathrm{O}_{2}$ at a longer time scale which resulted in a current decrease after the overshoot. The second pathway was governed by transfer processes of $\mathrm{H}^{+}$ions at the $\mathrm{TiO} / \mathrm{Nafion}_{2}$ interface and caused the observed current increase under illumination and positive relaxation in the dark, both at long time scales. A negative undershoot was observed when the reverse electrolysis reaction was preferred.

\section{INTRODUCTION}

The production of solar hydrogen $\left(\mathrm{H}_{2}\right)$ by photoelectrochemical (PEC) approaches is an intensively studied topic. Efforts have mainly been directed toward material research on individual components such as photoabsorbers, catalysts, and ion exchange membranes. To a lesser extent, the integration of the various components in a stand-alone assembly has been pursued. ${ }^{1}$ Nevertheless, understanding the interplay of the various components and the corresponding understanding of the coupled light absorption, charge separation, electrochemical reactions, and mass and charge transfer mechanisms in the components and the complete cells is crucial for practical PEC cells. Multiphysics modeling can significantly enhance the understanding of the functional interplay in PEC cells and help to quantify component requirements and optimal operating conditions for a high-performing PEC cell. ${ }^{2}$ Transient modeling can provide novel insight into the fundamental processes occurring at the photoabsorber interfaces. However, very few models investigated the transient behavior of a complete PEC cell. ${ }^{3}$ Electrochemical impedance spectroscopy is routinely used to investigate the properties of PEC cells in the frequency domain. ${ }^{4}$ We use transient photocurrent response for analysis in the time domain, which proved to be a complementary technique in other studies. ${ }^{5} \mathrm{We}$ aim at providing insight into the transient phenomena of a PEC cell composed of a monolithic membrane electrode assembly (MEA) incorporating a porous photoanode using a combined experimentalnumerical approach. Figure la shows a schematic of the investigated cell composed of a proton exchange membrane (Nafion), a dark cathode made of carbon fibers covered with $\mathrm{Pt}$ particles on carbon black (CB), and a photoanode composed of carbon fibers coated with nanoscale $\mathrm{TiO}_{2}$ particles by electrophoretic deposition.

$\mathrm{TiO}_{2}$ was not chosen for its performance (which is limited due to its large band gap) but rather as a reference material often used in the community. Its popularity stems from its abundance, nontoxicity, and chemically inertness. ${ }^{6}$ Its high band gap and the position of its conduction and valence bands also qualify its use for unassisted overall water splitting for $\mathrm{H}_{2}$ production. ${ }^{7}$ Yet, many aspects of $\mathrm{TiO}_{2}$ photoinduced

Received: December 20, 2015

Revised: January 25, 2016 

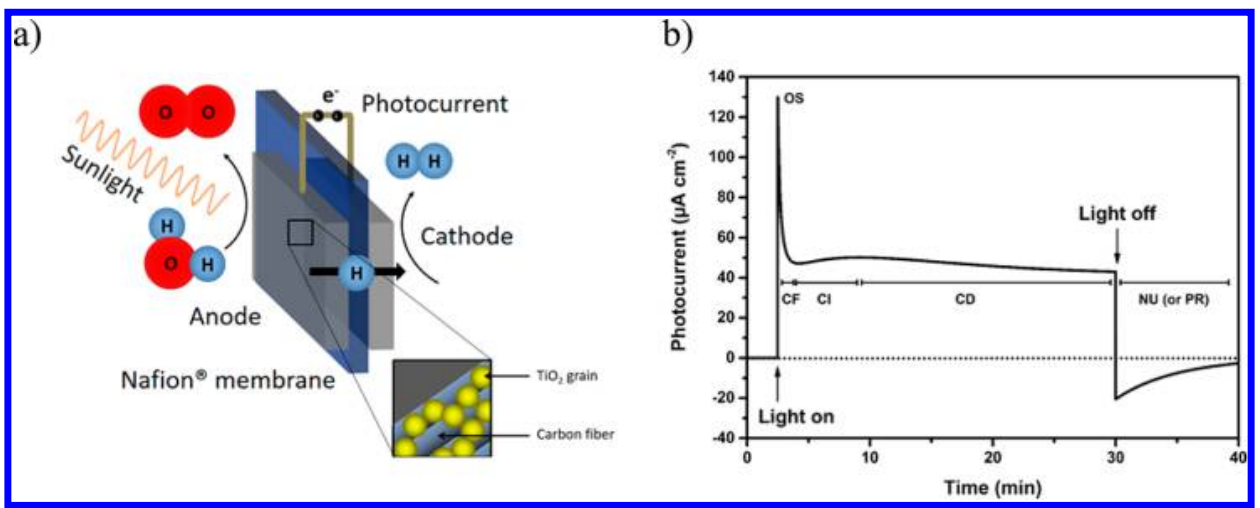

Figure 1. (a) Schematic of the investigated PEC cell consisting of a porous photoanode, proton-conducting membrane, and dark cathode. The photoanode is made of micrometer-scale carbon fibers covered with nanoscale $\mathrm{TiO}_{2}$ particles. (b) Illustrative representation of typical stages of the measured current: overshoot (OS), current fall (CF), current increase (CI), current decrease (CD), negative undershoot (NU), and positive relaxation (PR). The photocurrent is the electrical current measured in the metallic wire connecting the anode and cathode of the membrane electrode assembly.

mechanisms remain obscure, since the interaction of the material with metals, organic and inorganic mixtures changes the interface properties. ${ }^{8}$ Water oxidation mechanisms have been proposed for flat $\mathrm{TiO}_{2}$ interfaces ${ }^{9}$ but are still undecided. $^{10}$ In addition, models used for flat interfaces are not applicable to nanoporous $\mathrm{TiO}_{2}$ films since the diameter of the single particles are too small to allow for a space charge layer to develop, which is the driving force for charge carrier separation in flat semiconductors. ${ }^{6,11}$ Models specifically designed for dye-sensitized solar cells (DSSC) were developed, including detailed light absorption modeling ${ }^{12}$ and 1D models taking into account diffusion of charge carriers in the porous layer. ${ }^{9-15}$ However, the development of a transient cell model, involving the complex reactivity of nanoporous $\mathrm{TiO}_{2}$ surface, has not been developed yet. Nevertheless, the investigation of this transient behavior enriches the analysis and characterization of charge transfer mechanisms at the various photoabsorber interfaces, that is, semiconductor-electrolyte, semiconductor-semiconductor, and semiconductor-electrode interfaces. ${ }^{16}$

Rongé et al. ${ }^{17}$ experimentally assessed the transient photocurrent of a PEC cell using a $\mathrm{TiO}_{2}$ photoanode operated with different species mixture in the anodic and cathodic channels. They identified six characteristic transient response stages as shown in Figure 1b: fast overshoots (OS) after the illumination was switched on, longer current fall (CF), similarly long current increase (CI), longer current decay (CD), and after illumination was switched off, either a negative current undershoot followed by relaxation of the current to zero (NU), or a positive current relaxation (PR). The OS, CD, and NU stages have been generally observed for metallic electrodes in the transient response to a step change in applied potential and have been associated with the buildup of a charged layer at the metal-liquid interface. In membrane-separated electrolysis or fuel cells, these trends have been either explained by the rapid increase or decrease of species concentrations in the channels, ${ }^{18}$ different charge transfer coefficients of anodic and cathodic reactions, ${ }^{19}$ or voltage bias. ${ }^{20}$ In PEC devices, Zhang et al. $^{21}$ explained the transient photocurrent response of oxide films on stainless steel by drift-diffusion phenomena of charge carriers in the semiconductor material. However, under unbiased potential conditions, the transient response of these films exhibited a NU symmetrical to the OS whereas the NU observed for porous $\mathrm{TiO}_{2}-\mathrm{H}_{2} \mathrm{O}$ interfaces is generally less important in magnitude. ${ }^{16,17,22}$ The nonsymmetrical behavior between start-up and shut-down of these interfaces resulted from the complex, species-dependent chemistry of the porous $\mathrm{TiO}_{2}-\mathrm{H}_{2} \mathrm{O}$ interface and from the (varying) photopotential driven 2-electrode cell design. ${ }^{23}$ Understanding the origin of these different transient stages in a PEC cell is the objective of this investigation and is assessed by a coupled experimentalnumerical approach supported by a design of experiments (DOE).

Three parameters were tested in the DOE. Results from Rongé et al. have suggested ${ }^{17}$ that the overshoot could be related to adsorption of $\mathrm{H}_{2}$ on platinum at the cathode. Since the intensity of the shoot was not affected by the Nafion coverage at the anode, this suggested that the OS could partially or entirely be controlled by the cathode interface. The shoot, as well as the following decrease could be related to the variation of $\mathrm{H}-\mathrm{M}$ sites at the Pt covered cathode or by a change in Nernst equilibrium caused by the slowly increasing concentration of $\mathrm{H}_{2}$ in the cathode. ${ }^{24,25}$ We therefore assumed the OS and the amplitude of the steady state current included cathodic effects and we assessed these contributions by preconditioning of the cathode compartment with $\mathrm{H}_{2}$ gas (parameter 2). The influence of an acidic solution was also investigated by Rongé et al. ${ }^{17}$ and was shown to triple the value of the photocurrent when fed at the cathode and at the anode. They also noted that the CI could originate from a chemical bias generated by a proton gradient required for diffusion between the anode and the cathode. Since $\mathrm{pH}$ imposes a bias at the electrodes but is also involved into surface state equilibrium and reaction, we tested the influence of basic $\mathrm{pH}$ to complete and compare the data (parameter 1) and to assess the effect of the $\mathrm{Na}^{+}$ion on the photocurrent. Finally, temperature is involved into adsorption equilibrium and reaction kinetics. It can become significant in low current ranges $(\mu \mathrm{A})$ and could eliminate or modify one of the transient response stages. Results obtained for two temperature values can help identifying phenomena and understand the effect of temperature (parameter 3 ).

\section{MATERIALS, EXPERIMENTAL METHODS, AND TRANSIENT CURRENT MEASUREMENTS}

2.1. Materials. Milli- $Q$ water with a resistivity of $18.2 \mathrm{M} \Omega$ $\mathrm{cm}$ was used (Millipore). Nitrogen gas $\left(\mathrm{N}_{2}, 99.999 \%\right.$, Air Liquide, Brussels, Belgium) and $\mathrm{H}_{2}$ gas (99.9\%, Air Liquide) were purified (Varian CP17970 filter, Agilent, Santa Clara, CA) 
Table 1. Operating Parameters in Terms of Anode Chamber $\mathrm{pH}$, Temperature, and Cathode Preconditioning with $\mathrm{H}_{2}$ for the Eight Different Experimental Runs

\begin{tabular}{|c|c|c|c|c|c|c|c|c|}
\hline & \multicolumn{8}{|c|}{ parameter/run } \\
\hline & 1 & 2 & 3 & 4 & 5 & 6 & 7 & 8 \\
\hline $\mathrm{pH}$ in anode compartment & basic & neutral & basic & neutral & basic & neutral & basic & neutral \\
\hline $\mathrm{H}_{2}$ preconditioning of cathode & yes & yes & no & no & yes & yes & no & no \\
\hline$T\left({ }^{\circ} \mathrm{C}\right)$ & 60 & 60 & 60 & 60 & 25 & 25 & 25 & 25 \\
\hline
\end{tabular}

to remove all traces of $\mathrm{O}_{2}$ before usage. A stream of purified $\mathrm{N}_{2}$ was bubbled through a vessel with Milli-Q water at $20{ }^{\circ} \mathrm{C}$ to generate a gas stream with a water content of $0.017 \mathrm{mg} \cdot \mathrm{mL}^{-1}$. Nafion solution ( $20 \%$ in ethanol) and $\mathrm{NaOH}$ pellets were obtained from Sigma-Aldrich (St. Louis, MO). Toray carbon paper 030 was obtained from Fuel Cell Earth (Stoneham, MA). E-Tek $60 \%$ platinum/carbon black (Pt/CB) powder was from Umicore (Brussels, Belgium). Degussa P25 powder was obtained from Evonik (Essen, Germany). Nafion 117 proton exchange membrane was obtained from Quintech (Göppingen, Germany) and will be referred to as Nafion.

2.2. Preparation of Electrodes and Membrane Electrode Assembly (MEA). Preparation of anodes and cathodes was performed as previously reported. ${ }^{17}$ The photoabsorber coating is relatively thick and covers almost all carbon fibers. The penetration depth of UV light in P25 nanoparticles is lower than the thickness of our films, ${ }^{26}$ therefore parasitic light absorption in the carbon fibers is negligible. For three-electrode electrochemical characterization, the as-prepared $\mathrm{TiO}_{2}$ on carbon fiber paper was connected to a copper wire by depositing silver glue and letting it dry in air. A 2-component epoxy resin (Araldite K) was used to control the surface area exposed to the electrolyte. Nafion membranes were preconditioned according to an established procedure. ${ }^{27}$ Membrane electrode assemblies (MEA) were prepared by fixing the anode and cathode sheets on opposite sides of a pretreated Nafion membrane, adding a few drops of Nafion dispersion and hot-pressing between Teflon liners at $5 \mathrm{MPa}$ and $130{ }^{\circ} \mathrm{C}$ for $2.5 \mathrm{~min}$. After hot-pressing, the assembly was carefully removed from the liners and allowed to cool in a stainless steel holder. The assembly was then washed for $1 \mathrm{~h}$ at $60{ }^{\circ} \mathrm{C}$ in Milli-Q water to remove any residual solvent. ${ }^{28}$ SEM images (see Figure S8 in the Supporting Information) were obtained with a Nova NanoSEM 450 instrument (FEI, Hillsboro, OR).

2.3. Electrochemical Characterization of Electrodes. 3electrode electrochemical experiments (impedance spectroscopy and cyclic voltammetry) were performed using a homemade Teflon holder to keep all electrodes at equal distance during the experiments in order to ensure a similar electrolyte resistance. $\mathrm{TiO}_{2}$ nanoparticles on carbon fiber substrate served as the working electrode (WE), a Pt mesh as counter electrode (CE) and an $\mathrm{Ag} / \mathrm{AgCl}(3 \mathrm{M} \mathrm{KCl}$, sat. $\mathrm{AgCl}$, Radiometer Analytical) reference electrode was used. One $\mathrm{M} \mathrm{H}_{2} \mathrm{SO}_{4}$ was used as electrolyte. The holder was placed inside a glass container which contained a quartz window allowing for direct illumination. The solution was vigorously stirred with a magnetic stirrer while bubbling a high $\mathrm{N}_{2}$-flow through the solution for $10 \mathrm{~min}$ before every experiment. During the experiments, the $\mathrm{N}_{2}$ purge was reduced and the stirring was lowered to a minimum speed.

2.4. Photoelectrochemical Experiments. The studied MEA was inserted in a homemade photoelectrochemical (PEC) cell consisting of a graphite flow-field plate at the cathode compartment and a homemade fused silica plate at the photoanode side. ${ }^{17}$ The fused-silica plate and the graphite plate contained serpentine flows providing an optimal contact of the fluid with the electrode surface. After insertion of the MEA in the PEC cell, a cleaning protocol was performed. The anode compartment was fed with $\mathrm{N}_{2}$-purged Milli-Q water $(0.75 \mathrm{~mL}$ $\mathrm{min}^{-1}$ ) using a peristaltic pump (Watson Marlow, Wilmington, MA). The cathode was purged with deoxygenized and humidified $\mathrm{N}_{2}\left(20 \mathrm{~mL} \min ^{-1}\right)$. The system was purged overnight (at least $15 \mathrm{~h}$ ) before making electrical contact. After this pretreatment, the cell was short circuited and the dark current monitored. The dark current quickly evolved to an equilibrium, which we defined as reached when only minor variations $\left(0 \pm 250 \mathrm{nA} \mathrm{cm}^{-2}\right)$ in dark current were observed for at least $5 \mathrm{~min}$.

In a standard experiment, a continuous flow of $\mathrm{N}_{2}$-purged Milli-Q water was pumped through the anode compartment at a rate of $0.75 \mathrm{~mL} \mathrm{~min}{ }^{-1}$. For experiments with basic $\mathrm{pH}$ at the anode compartment, a $1 \mathrm{M} \mathrm{NaOH}$ solution in Milli-Q water was used but here the experiment was started immediately to avoid quick contamination of the membrane with $\mathrm{Na}^{+}$ions. At the cathode side a $\mathrm{N}_{2}$ gas flow was always used $\left(20 \mathrm{~mL} \mathrm{~min}^{-1}\right)$. The cell was illuminated with a broad spectrum Xe lamp with IR filter (200-750 nm; Oriel 66984, Newport, Irvine, CA) adjusted such that the incident intensity was $100 \mathrm{~mW} \mathrm{~cm}^{-2}$. Temporal resolution of the recorded photocurrent was $1 \mathrm{~s}$ using a potentiostat (Versastat 4, Princeton Applied Research, Oak Ridge, TN) and Versastudio electrochemical analysis software. A higher temporal resolution of $1 \mathrm{~ms}$ was used for 10 $s$ during changes in illumination (switching on and off) in order to obtain more detailed overshoot and undershoot data. Note that periodic oscillation of the photocurrent was observed, which was associated with the operation of the peristaltic pump, feeding liquid water to the anode compartment. Chopping of light was done manually at intervals with decreasing frequency.

For experiments at elevated temperature, a heating pad was placed on the outer side of the cathode compartment. The cell was wrapped in insulating material and the temperature of the pad was kept at $70{ }^{\circ} \mathrm{C}$ using a thermocouple and temperature controller. A second temperature sensor monitored the temperature inside the cell, close to the sample surface. Before illumination, the inside of the cell reached a constant temperature of $60{ }^{\circ} \mathrm{C}$.

Experiments with $\mathrm{H}_{2}$ at the cathode side were performed in the same manner. First the pure $\mathrm{H}_{2}$ flow was turned on until it reached the cathode side of the cell. This was obvious due to the sudden drop of the steady state current of the cell at short circuit (see the Supporting Information). This negative current descended to a minimum and at this time the $\mathrm{H}_{2}$ flow was turned off. The cell was then left flushing with $\mathrm{N}_{2}$ until a steady state was reached, assumingly leaving the cathode side fully hydrogenated (see the Supporting Information).

Eight experiments using different conditions were conducted and are detailed in Table 1 . These experiments include all the 
possible configurations generated by the two possible levels of the three investigated parameters $\left(\mathrm{pH}\right.$, temperature, $\mathrm{H}_{2}$ preconditioning).

\section{MODEL DEVELOPMENT AND GOVERNING EQUATIONS}

Even though the time scales of the CF, CI, and CD are in the order of typical mass transfer phenomena (10-1000 s), a model accounting for drift-diffusion of species in the channel and charge in the semiconductor using Butler-Volmer kinetics and a Nernstian dependence of potentials on the concentration of species, as done for porous hematite photoelectrodes, ${ }^{3}$ was not successful in predicting the transient behavior. Wang and $\mathrm{Ku}^{22}$ have shown that the available potential at the $\mathrm{TiO}_{2}-\mathrm{H}_{2} \mathrm{O}$ interface was following a non-Nernstian behavior with $\mathrm{pH}$, suggesting the presence of surface-based species and charge interactions and accumulation. ${ }^{22}$ Impedance spectroscopy measurements of the PEC cell, as shown in Figure S7, revealed a nonlinear capacitive behavior of the anodic interface, supporting the idea of charge carrier accumulation at interfaces. ${ }^{29}$ We consequently introduced a model for surface states, which are expected due to the reactivity and high surface-to-volume-ratio of the porous electrode. ${ }^{6}$

Previous experimental results from Rongé et al. suggested that the photocurrent was controlled by two parallel adsorption processes. ${ }^{17}$ Light chopping experiments showed that the transient process controlling the CI was not affected when illumination was chopped. By contrast, the magnitude of the OS was very sensitive on the chopping pattern and needed a long dark period $(\sim 30 \mathrm{~min})$ to recover its maximum value. ${ }^{17}$ Moreover, when an additional layer of Nafion was cast on top of the anode, CI dominated the photocurrent and provided values larger than the OS itself. In this case, no NU was observed and CI and PR stages showed a similar time scale, suggesting that these two phenomena occur at the same interface and are controlled by the same species. Wang and $\mathrm{Ku}$ have shown that the $\mathrm{TiO}_{2}-$ Nafion interface had a different reactivity compared to the $\mathrm{TiO}_{2}-\mathrm{H}_{2} \mathrm{O}$ interface, reinforcing the idea of two parallel transfer paths at each interface. ${ }^{30} \mathrm{We}$ assumed that the photocurrent was utilized in two parallel electrochemical pathways: Transfer path 1 was related to the OS and the CF while transfer path 2 explained the CI and the PR. We introduced two placeholder species, $A$ and $B$, involved in the surface state trapping and transfer of electrons. The surface states are described as available slots on the interface to which species $A$ and $B$ bound and form reactive sites, $S_{A}$ and $S_{B}$,

$$
\begin{aligned}
& A+S \rightarrow S_{A} \\
& B+S \rightarrow S_{B}
\end{aligned}
$$

Assuming fast equilibrium, the fraction of filled states, $n_{A}$ and $n_{B}$ is given by the Langmuir adsorption model, ${ }^{31}$

$$
\begin{aligned}
& n_{\mathrm{A}}=\frac{S_{A}}{S_{1}}=\frac{K_{A} c_{A}}{1+K_{A} c_{A}} \\
& n_{B}=\frac{S_{B}}{S_{2}}=\frac{K_{\mathrm{B}} c_{B}}{1+K_{\mathrm{B}} c_{B}}
\end{aligned}
$$

utilizing the equilibrium constants, $K_{A}$ and $K_{B}$, the maximum number of available interface states for path 1 and $2, S_{1}$ and $S_{2}$, and the concentrations of species $\mathrm{A}$ and $\mathrm{B}, c_{A}$ and $c_{B}$. This approach was consistent with the capacity of $\mathrm{TiO}_{2}$ to adsorb numerous species to create interface states with high reactivity, and with previous accumulation models proposed for DSSCs. $^{23,32,33}$ The reaction rates for paths 1 and $2, r_{\mathrm{A}}$ and $r_{\mathrm{B}}$, are given as

$$
\begin{aligned}
& r_{A}=\phi k_{1}\left(1-n_{\mathrm{A}}\right) \\
& r_{B}=\phi k_{2} n_{B}
\end{aligned}
$$

where the illumination coefficient, $\phi$, equals one if illumination is switched on and zero otherwise. The rate constants of path 1 and $2, k_{1}$ and $k_{2}$, are material and operational specific constants. The evolution of the reactive states was modeled by mass continuity,

$$
\begin{aligned}
& \frac{\mathrm{d} c_{A}}{\mathrm{~d} t}=\eta_{A}\left(r_{A}+r_{B}\right)-k_{A}\left(c_{A}-c_{A_{\text {in }}}\right) \\
& \frac{\mathrm{d} c_{B}}{\mathrm{~d} t}=\eta_{B}\left(r_{A}+r_{B}\right)-k_{\mathrm{B}}\left(c_{B}-c_{B_{\text {in }}}\right)
\end{aligned}
$$

$\eta_{A}$ is a coefficient involving the effects of Faradaic efficiency and stoichiometry. $k_{A}$ and $k_{B}$ are mass transfer constants, and $c_{A_{\text {in }}}$ and $c_{B_{\text {in }}}$ are the inlet concentrations of $A$ and $B$ in the anodic channel. Experimental results from Modestino et al. showed that the steady state current increased with increasing velocity in the channels, ${ }^{34}$ supporting the importance of mass transfer in the transient pattern, in addition to the long time scales of the transient pattern stages.

The NU has been shown to result from the reverse electrolysis reaction between cathodic $\mathrm{H}_{2}$ with anodic $\mathrm{O}_{2}{ }^{17}$ The reverse electrolysis reaction was assumed to obey the following kinetic equation, with the order of the reactants corresponding to their stoichiometric coefficients.

$$
r_{\text {rec }}=\left[\phi k_{\text {rec,l }}+(1-\phi) k_{\text {rec,d }}\right] c_{\mathrm{O}_{2}}^{\text {a } 1 / 4} c_{\mathrm{H}_{2}}^{\mathrm{c}}{ }^{1 / 2}
$$

Two recombination rates, $k_{\text {rec, } 1}$ during illuminated operation and $k_{\text {rec,d }}$ during dark operation, were predicted, suggesting that recombination during illumination is governed by a different process than in the dark, where only the reverse electrolysis (fuel cell) reaction is assumed to take place.

The concentrations of $\mathrm{H}_{2}$ and $\mathrm{O}_{2}$ at the cathode, as well as $\mathrm{O}_{2}$ at the anode, are governed by species transport and conservation equations, accounting for reaction and convection-diffusion phenomena:

$$
\begin{aligned}
\frac{\mathrm{d} c_{\mathrm{O}_{2}}^{\mathrm{a}}}{\mathrm{d} t} & =\eta_{\mathrm{O}} r-k_{\mathrm{O}}\left(c_{\mathrm{O}_{2}}^{\mathrm{a}}-c_{\mathrm{O}_{2, \mathrm{in}}}^{\mathrm{a}}\right) \\
\frac{\mathrm{d} c_{\mathrm{H}_{2}}^{\mathrm{c}}}{\mathrm{d} t} & =\eta_{\mathrm{H}} r-k_{\mathrm{H}}\left(c_{\mathrm{H}_{2}}^{\mathrm{c}}-c_{\mathrm{H}_{2, \mathrm{in}}}^{\mathrm{c}}\right)
\end{aligned}
$$

$c_{\mathrm{O}_{2, \text { in }}}^{\mathrm{a}}$ and $c_{\mathrm{H}_{2, \text { in }}}^{\mathrm{c}}$ being the inlet concentration of anodic $\mathrm{O}_{2}$ and cathodic $\mathrm{H}_{2}$, respectively. $k_{\mathrm{O}}$ and $k_{\mathrm{H}}$ are mass transfer constants. Since $\mathrm{O}_{2}$ and $\mathrm{H}_{2}$ concentrations are always low during the measurements, crossover is neglected. $r$ is the total reaction rate, given as the sum of these rates, and is related to the photocurrent as

$$
r=r_{A}+r_{B}-r_{\text {rec }}=i_{\mathrm{ph}} / F
$$

We nondimensionalized the equation system with the reaction rate $r_{0}=5.18 \times 10^{-10} \mathrm{~mol} \mathrm{~m} \mathrm{~m}^{-2} \mathrm{~s}^{-1}$, corresponding to a photocurrent of $i_{0}=50 \mu \mathrm{A} \mathrm{cm} \mathrm{cm}^{-2}$, to extract proportionality constants and characteristic times from the parameters of the model. The nondimensionalization of the equation system is 


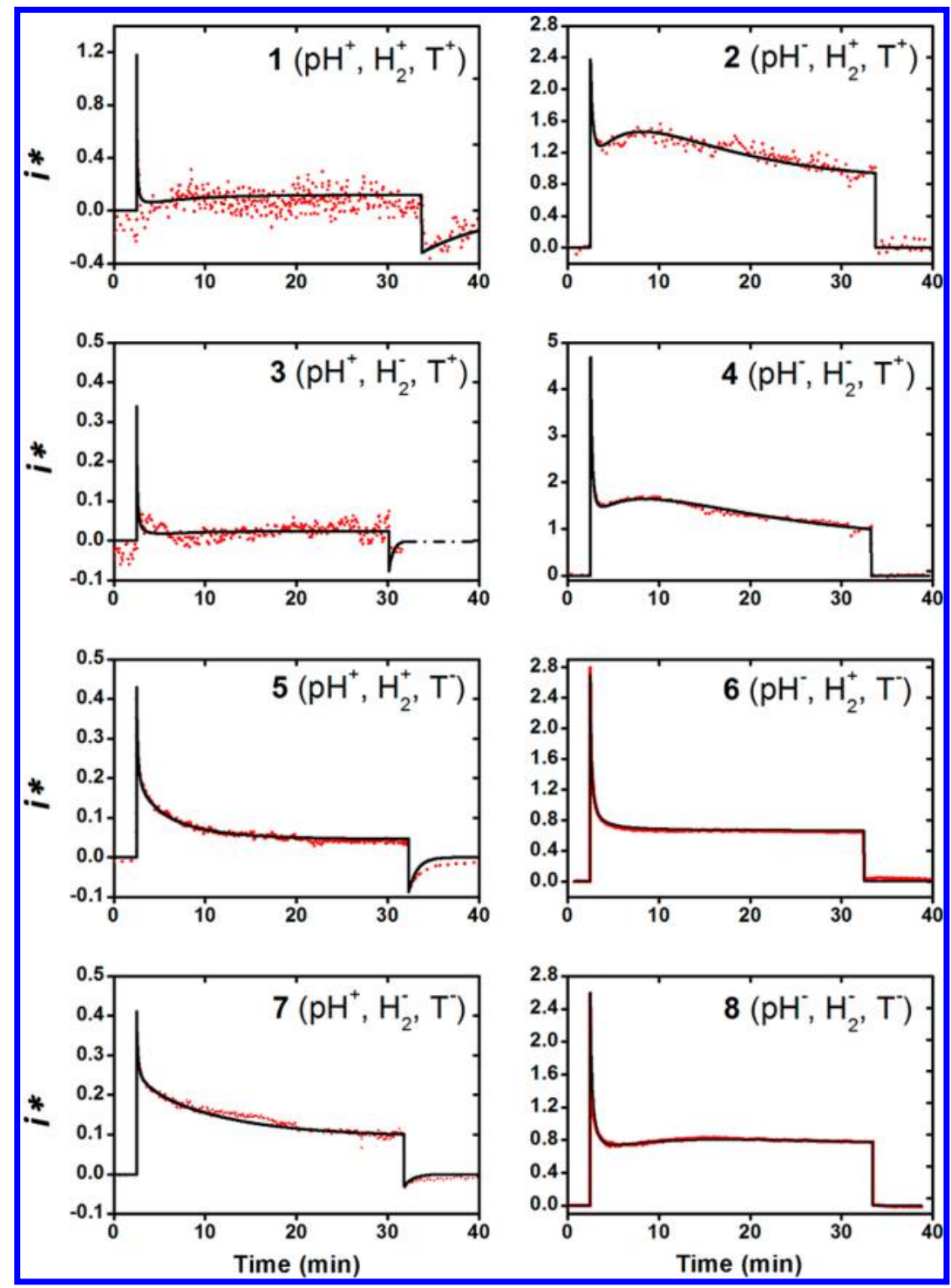

Figure 2. Measured (red, dotted line) and modeled (black, solid line) transient dimensionless photoelectrochemical transfer rates for experimental runs 1 to 8 , as defined in Table 1 . The photocurrent is nondimensionalized with the reference photocurrent $i_{0}=50 \mu \mathrm{A} \mathrm{cm}{ }^{-2}$. Experimental conditions in brackets with a plus sign for basic $\mathrm{pH}, \mathrm{H}_{2}$ preconditioning, and high temperature, and a minus sign otherwise.

presented in the ESI. $\tau_{\mathrm{ads}, A}=\left(K_{A} r_{0}\right)^{-1}$ and $\tau_{\mathrm{ads}, B}=\left(K_{B} r_{0}\right)^{-1}$ represent the characteristic adsorption time of species $A$ and $B$, and $r_{1}^{*}=k_{1} / r_{0}, r_{2}^{*}=k_{2} / r_{0}, r_{\text {rec, } 1}^{*}=k_{\text {rec, }, 1} / r_{0}^{1 / 4}$, and $r_{\text {rec,d }}^{*}=k_{\text {rec, } \mathrm{d}} / r_{0}^{1 / 4}$ are the dimensionless reaction rate constants for path 1 and 2 and for the recombination reactions under illuminated and dark operation. This way, the dimensionless photocurrent $i^{*}=i / i_{0}$ is equal to the dimensionless reaction rate $r^{*}=r / r_{0}$.

\section{RESULTS}

4.1. Transient Current Measurements. Figure 2 shows the measured transient current response (red, dotted lines) for the eight experimental runs with no potential bias. To clearly visualize the difference between the runs, the measured transient currents were nondimensioned with $i_{0}$. Before any numerical analysis is performed, qualitative observation could be made on the effect of parameters and their combination.

The combination of elevated temperature and alkaline $\mathrm{pH}$ anode chambers (runs 1 and 3) caused extremely unstable current responses and larger OS with faster current decrease and absence of $\mathrm{CI}$ and $\mathrm{CD}$. The combination of elevated temperatures and neutral $\mathrm{pH}$ (runs 2 and 4) caused a less unstable current response with a clear observation of $\mathrm{CI}$ and CD.

The effect of $\mathrm{H}_{2}$ preconditioning (runs 1, 2, 5, and 6) on the OS was not significant at room temperature but had an opposite effect at high temperature: the value of the OS increased with $\mathrm{H}_{2}$ preconditioning in a basic anode (runs 1 and 3 ), whereas it decreased in a neutral $\mathrm{pH}$ anode (runs 2 and 4). The steady state and decaying currents were not affected by $\mathrm{H}_{2}$ preconditioning in neutral $\mathrm{pH}$ conditions (less than $5 \%$ variation).

The effect of anodic basic $\mathrm{pH}$ was most influential. In neutral $\mathrm{pH}$, the OS current and the steady state current were significantly higher than in alkaline operation (OS was 2 to 14 times higher and steady state current was 8 times higher, between two similar cases with different $\mathrm{pH}$ ). NU was much lower or almost completely suppressed. The ratio between maximum negative and positive current was much larger $(10 \%$ for run 7 and above $20 \%$ for the others) in basic conditions than in neutral conditions ( $5 \%$ for case 2 and below $1 \%$ for the 
Table 2. Fitting Parameters of the Model

\begin{tabular}{|c|c|c|c|c|c|c|c|c|}
\hline & \multicolumn{8}{|c|}{ experiment } \\
\hline & 1 & 2 & 3 & 4 & 5 & 6 & 7 & 8 \\
\hline$\tau_{\mathrm{ads}, A}=\tau_{\mathrm{CF}}(\mathrm{min})$ & 0.03 & 0.37 & 0.13 & 0.17 & 0.12 & 0.11 & 0.17 & 0.25 \\
\hline$\tau_{\mathrm{ads}, B}(\min )$ & 100 & 3.3 & 100 & 2.5 & 0.14 & 0.11 & 0.25 & 2 \\
\hline$r_{1}^{*}=r_{\mathrm{OS}}^{*}$ & 1.18 & 2.38 & 0.2 & 5 & 0.43 & 2.7 & 0.41 & 2.6 \\
\hline$r_{2}^{*}$ & 2 & 2.4 & 0.3 & 2.5 & 0.13 & 0.65 & 0.21 & 0.6 \\
\hline$r_{\mathrm{rec}, 1}^{*}$ & 0 & 0.7 & 0 & 0.5 & 1.1 & 0 & 0.9 & 0 \\
\hline$r_{\text {rec,d }}^{*}$ & 0.5 & 0 & 5 & 0 & 1 & 0 & 0.2 & 0 \\
\hline$r_{\mathrm{OS}}^{*} \tau_{\mathrm{CF}}(\mathrm{min})$ & 0.04 & 0.88 & 0.025 & 0.83 & 0.05 & 0.3 & 0.07 & 0.65 \\
\hline
\end{tabular}

other). $\mathrm{CI}$ was more visible in neutral $\mathrm{pH}$, and $\mathrm{CD}$ was absent for cases with low temperature and neutral $\mathrm{pH}$ operation (runs 6 and 8 ).

4.2. Modeling Results. The parameters of the model presented in paragraph 3 were fitted to the experiments for each run (see Table 2). This approach revealed that adsorption times, $\tau_{\mathrm{ads}, A}$ and $\tau_{\mathrm{ads}, B}$, and dimensionless reaction rates constants, $r_{1}^{*}, r_{2}^{*}, r_{\text {rec, },}^{*} r_{\text {rec,d }}^{*}$, were dependent on the operational conditions. Other parameters could be kept constant: Stoichiometric coefficients $\eta_{i}$ were set to 1 for species $A$ and $B$, while naturally set to 0.5 for $\mathrm{H}_{2}$ and 0.25 for $\mathrm{O}_{2} . k_{A}$ and $k_{B}$ were fitted to light chopping experiments, ${ }^{17}$ as shown in Figure 3. The obtained rates could be kept constant for experimental

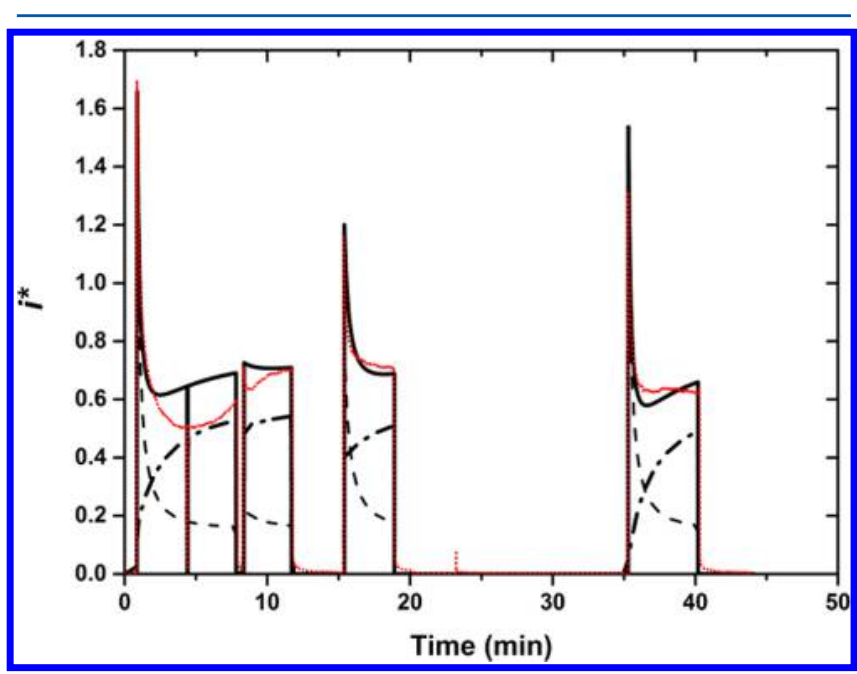

Figure 3. Previously measured ${ }^{17}$ (red, dotted) and modeled (black, solid) dimensionless photocurrents during a light chopping experiment for conditions as in run 8 (low temperature, no pretreatment, neutral $\mathrm{pH}$; see Table 1). Modeled current is the sum of the parallel currents in path 1 (black, dashed line) and path 2 (black, dash dot line). runs $1-7\left(k_{A}=0.6 \mathrm{~min}^{-1}\right.$ and $\left.k_{B}=0.2 \mathrm{~min}^{-1}\right)$, but needed to be adapted for run 8 were a lower value of $k_{A}=0.001 \mathrm{~min}^{-1}$ was needed. The initial concentrations of species $A$ and $B$ were set to zero.

Fitting the parameters of the model to the experimental results further revealed their direct connection to the different stages of the photocurrent transients: $r_{1}^{*}=r_{\mathrm{OS}}^{*}$ and $\tau_{\mathrm{ads}, A}=\tau_{\mathrm{CF}}$ represent the dimensionless intensity of the OS and characteristic time of the $\mathrm{CF}$, respectively. However, no clear connection could be made between the characteristic time of the CI and the adsorption time $\tau_{\mathrm{ads}, B}$.

The observation that $\tau_{\mathrm{ads}, A}$ remained in the same order of magnitude $(\sim 0.1 \mathrm{~min})$ for all the experimental operating conditions (runs 1 to 8 ) suggests that path 1 is not driven by an adsorption phenomenon. This observation was reinforced by the low value of $\tau_{\text {ads }, A}$ compared to $\tau_{A}=c_{A} / r_{0}$ (between 4 to 55 times lower) which allowed to rewrite eq $3 \mathrm{a}$ in the simplified form $r_{A}^{*} \approx \phi r_{1}^{*} \tau_{\text {ads, } A} / \tau_{A}$, suggesting that the reactivity of path 1 follows a dependence on $c_{A}{ }^{-1}$ with a dimensionless characteristic reaction rate equal to $r_{1}^{*} \tau_{\mathrm{ads}, A}=r_{\mathrm{OS}}^{*} \tau_{\mathrm{CF}}$. On the contrary, $\tau_{\mathrm{ads}, B}$ was strongly influenced by temperature, suggesting that a lower temperature strongly favors the adsorption equilibrium of $B$. This observation is consistent with the temperaturedependence of adsorption phenomena.

4.3. Design of Experiment. In order to reveal additional dependencies between the parameters of the model with operating conditions, we further performed a design of experiments (DOE). The DOE was used to extract and quantify separated and coupled influences of the operating parameters ( $\mathrm{pH}$, temperature, and $\mathrm{H}_{2}$ preconditioning) on the model parameters. We performed a $2^{3}$ full factorial design ( 3 parameters tested on two levels) and built a first order correlation between the parameters of the model $p$ and the operational parameters with coefficients $a$ :

Table 3. Mean Value and Weight of Operational Parameters on Model Fitting Parameters Obtained by DOE

\begin{tabular}{|c|c|c|c|c|c|c|c|c|}
\hline & \multicolumn{8}{|c|}{ model parameter } \\
\hline & $p_{0}$ & $w_{\mathrm{pH}}$ & $w_{\mathrm{H}_{2}}$ & $w_{T}$ & $w_{\mathrm{pH}, \mathrm{H}_{2}}$ & $w_{\mathrm{pH}, T}$ & $w_{\mathrm{H}_{2} T}$ & $w_{\mathrm{pH}, T, \mathrm{H}_{2}}$ \\
\hline$\tau_{\mathrm{ads}, A}=\tau_{\mathrm{CF}}(\min )$ & 0.17 & -0.3 & -0.1 & 0 & -0.2 & -0.2 & 0.2 & -0.3 \\
\hline$\tau_{\mathrm{ads}, B}(\min )$ & 26 & 0.9 & 0 & 1 & 0 & 0.9 & 0 & 0.0 \\
\hline$r_{1}^{*}=r_{\mathrm{OS}}^{*}$ & 1.86 & -0.7 & -0.1 & 0.2 & 0.2 & -0.1 & -0.1 & 0.2 \\
\hline$r_{2}^{*}$ & 1.01 & -0.4 & 0.2 & 0.6 & 0.2 & -0.2 & 0.2 & 0.2 \\
\hline$r_{\text {rec,1 }}^{*}$ & 0.4 & 0.3 & 0.1 & -0.3 & 0 & -1 & 0 & -0.1 \\
\hline$r_{\text {rec,d }}^{*}$ & 0.84 & 1 & -0.6 & 0.6 & -0.6 & 0.6 & -0.8 & -0.8 \\
\hline$r_{\mathrm{OS}}^{*} \tau_{\mathrm{CF}}(\min )$ & 0.36 & -0.9 & -0.1 & 0.2 & 0.1 & -0.3 & 0.2 & -0.1 \\
\hline
\end{tabular}




$$
\begin{aligned}
p= & p_{0}\left(1+w_{\mathrm{pH}} a_{\mathrm{pH}}+w_{\mathrm{H}_{2}} a_{\mathrm{H}_{2}}+w_{T} a_{T}+w_{\mathrm{pH}, \mathrm{H}_{2}} a_{\mathrm{pH}} a_{\mathrm{H}_{2}}\right. \\
& \left.+w_{\mathrm{pH}, T} a_{\mathrm{pH}} a_{T}+w_{\mathrm{H}_{2}, T} a_{\mathrm{H}_{2}} a_{T}+w_{\mathrm{pH}, \mathrm{H}_{2}, T} a_{\mathrm{pH}} a_{\mathrm{H}_{2}} a_{T}\right)
\end{aligned}
$$

Coefficients $a$ take two values depending on the choice of the related operational parameters during the run: -1 for neutral $\mathrm{pH}$, ambient temperature, or no $\mathrm{H}_{2}$ preconditioning, and +1 otherwise. The dimensionless weights, $w$, of each parameter for all the relevant parameters of the model are indicated in Table 3. The influence of an experimental parameter on a model parameter was quantified by the absolute value of a weight. A negative weight indicates that an increase in the parameter results in a decrease of the model parameter, and vice versa for a positive weight. $p_{0}$ is the mean value of the parameter over the eight runs.

DOE results confirmed the importance of $\mathrm{pH}$ on the intensity of the OS, since the absolute $w_{\mathrm{pH}}$ was much larger for $r_{\mathrm{OS}}^{*}$ and $r_{\mathrm{OS}}^{*} \tau_{\mathrm{CF}}(-0.7$ and -0.9$)$ than any other weights for other single parameters $\left(-0.1\right.$ and 0.2 for $w_{\mathrm{H} 2}$ and $\left.w_{\mathrm{T}}\right) . w_{\mathrm{pH}}$ was negative, indicating that an increase in the $\mathrm{pH}$ decreases the $\mathrm{OS}$ amplitude, as observed previously. The amplitude of the weights for coupled parameters were low for $r_{\mathrm{OS}}^{*}$ and $r_{\mathrm{OS}}^{*} \tau_{\mathrm{CF}}$ (between 0.1 and 0.3 ), indicating that the effect of $\mathrm{pH}$ was mostly independent of the other operational conditions, suggesting that path 1 could be related to an acid-base equilibrium. $\tau_{\mathrm{ads}, B}$ was strongly increased with an increase in $\mathrm{pH}$ $\left(w_{\mathrm{pH}}=0.9\right)$ or temperature $\left(w_{\mathrm{T}}=1\right)$, and not dependent on $\mathrm{H}_{2}$ preconditioning $\left(w_{\mathrm{H} 2}<0.05\right)$. The interaction between temperature and $\mathrm{pH}$ was important $\left(w_{\mathrm{pH}, T}=1\right)$, suggesting that the adsorption of $B$ is a $\mathrm{pH}$-controlled phenomenon, or controlled by a species only present in basic conditions. $r_{2}^{*}$ was negatively impacted by an increase in $\mathrm{pH}\left(w_{\mathrm{pH}}=-0.4\right)$, and positively impacted by an increase in temperature $\left(w_{T}=0.6\right)$ and $\mathrm{H}_{2}$ preconditioning $\left(w_{\mathrm{H}_{2}}=0.2\right)$. Interaction parameters were of the same magnitude (0.2) suggesting that the kinetics of path 2 is controlled by a phenomena involving both the cathode and the anode, and negatively affected by a basic $\mathrm{pH}$. The recombination rate $r_{\text {rec, } 1}^{*}$ during illuminated operation showed an equal but opposite dependency on $\mathrm{pH}$ and $T\left(w_{\mathrm{pH}}=\right.$ $\left.-w_{T}=0.3\right)$. The influence of $\mathrm{H}_{2}$ preconditioning was less important $\left(w_{\mathrm{H}_{2}}=0.1\right)$ and was disconnected from the process that involves $\mathrm{pH}$ and temperature $\left(w_{\mathrm{pH}, \mathrm{H}_{2}}=w_{\mathrm{H}_{2}, T}=0\right)$. This suggests that the recombination is also related to an adsorption phenomena similar to path 2 . Recombination in dark mode is controlled by $\mathrm{pH}, \mathrm{H}_{2}$ preconditioning, and temperature with a strong interaction between these parameters, confirming a reverse electrolysis reaction caused by a difference in Nernst potential between the anode and the cathode.

4.4. Experimental Support of Current Stages and Transfer Path Description. Figure 4 shows the measured current profile of the MEA inside the PEC cell at an applied bias of $2 \mathrm{~V}$ in a two-electrode setup. The transient current phenomena are quite similar to its unbiased illuminated counterparts (Figure 2, run 8), but some significant differences can be observed. The overall current value is about 2 orders of magnitude higher with a steady state current of $2 \mathrm{~mA} \mathrm{~cm}-2$ which is an acceptable current in terms of water splitting reaction rate given the applied potential. When compared to the observed currents in the illuminated experiments, it is clear that the developed photopotential of the $\mathrm{TiO}_{2}$ photoanode is small and variable over time. Therefore, transient effects $\mathrm{CI}$,

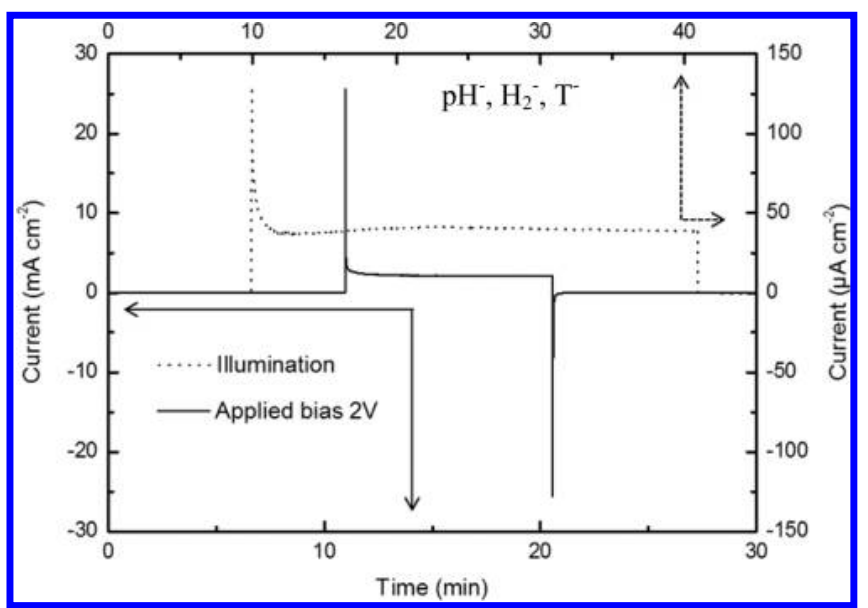

Figure 4. Chronoamperometric curve of an MEA inside the PEC cell (run 8: $\mathrm{pH}^{-}, \mathrm{H}_{2}^{-}, \mathrm{T}^{-}$) in dark at an applied bias of $2 \mathrm{~V}$ (solid line) and under illumination without an applied bias (dotted line).

$\mathrm{CD}$, and $\mathrm{PR}$ are not observed when a larger and constant potential is applied to the system. Additionally, the OS and NU are symmetrical opposed to an illuminated experiment. This confirms that the bias forced the presence of NU, and explains the symmetrical behaviors of the transient response under bias observed by Zhang et al. ${ }^{21}$

A closer look at the OS in the experiments (Figure 5) revealed that the shoot follows an exponential or autocatalytic trend with a rising time of $0.2-0.3 \mathrm{~s}$ with a sharp rise in basic conditions. This suggests that the reactive sites in path 1 would be quickly filled by charge carriers at start-up. As $c_{A}$ increases, the number of available sites diminishes. When light is switched off, $c_{A}$ decreases, allowing more sites to be active again.

\section{DISCUSSION}

5.1. Path 1: Overshoot (OS) and Current Fall (CF). The possible idea that the OS and the CF are controlled by cathodic phenomena was dismissed, as DOE results suggest that path 1 is an anodic and $\mathrm{pH}$-related phenomenon. This idea had already been put forward by Wang and $\mathrm{Ku}$, who observed the reduction of the OS intensity inversely proportional to anodic $\mathrm{pH}$, for systems using bare and Nafion-coated $\mathrm{TiO}_{2}$ electrode for photocatalytic reactions of dyes. ${ }^{22}$ This effect was attributed to the lower amount of acidic titanol groups ${ }^{7}$ at the $\mathrm{TiO}_{2}-\mathrm{H}_{2} \mathrm{O}$ interface $\left(-\mathrm{OH}_{2}{ }^{+}\right)$that form when a $\mathrm{TiO}_{2}$ interface is put in contact with water. ${ }^{35}$ This idea is consistent with the high OS value observed by Rongé et al. ${ }^{17}$ when the anode was fed with $\mathrm{H}_{2} \mathrm{SO}_{4}$. The results indicated that the formation of such surface states is favored by the presence of holes in the semiconductor. As predicted from the DOE, path 1 would be a photoinduced acid-base equilibrium. At start-up, the shoot results from the quick formation of acidic titanol groups coming from the fast generation of holes and abundant water availability on the surface. In basic conditions, $\mathrm{OH}^{-}$ions favors the consumption of these sites, accelerating their renewal by generated holes, and thermodynamically reducing their maximum number at equilibrium, explaining the lower OS time and intensity observed for basic conditions in Figure 5.

We hypothesize that the CF stage is related to the concentration buildup of a species near the $\mathrm{TiO}_{2}$ surface that diminishes the activity or the number of titanol groups. Previous results provided some evidence that this species could be anodic $\mathrm{O}_{2}$. Indeed the presence of $\mathrm{O}_{2}$ traps electrons to form 


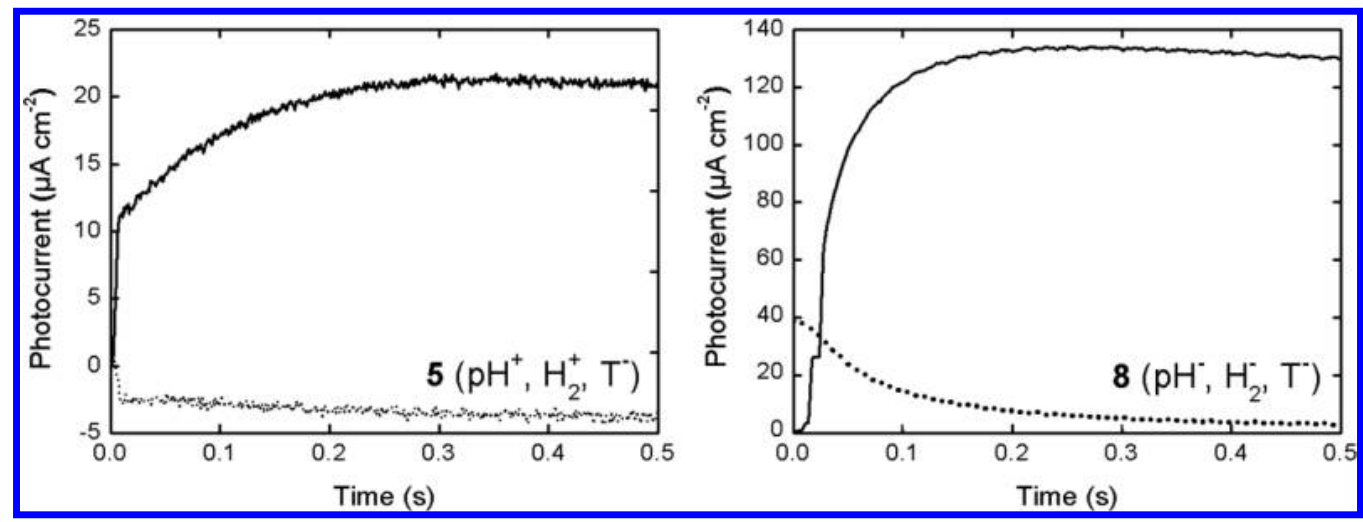

Figure 5. Detailed look at the OS (solid line) and PR (dotted line) photocurrents for experimental runs 5 and 8.

peroxide radicals that consume titanol groups. ${ }^{30}$ Rongé et al. also observed that the OS and CF stages are unseen when the anode is fed with $\mathrm{H}_{2} \mathrm{O}_{2}$. This species acts as a catalyst in the interfacial charge transfer during the $\mathrm{O}_{2}$ evolution reaction ${ }^{23}$ and would impose a parallel reaction mechanism in which titanol groups would not be involved. By becoming the catalyzer of the reaction, $\mathrm{H}_{2} \mathrm{O}_{2}$ would ensure the removal of holes that would be normally required to form the titanol groups.

$$
\begin{aligned}
& 2 h_{\mathrm{vb}}^{+}+2 \mathrm{H}_{2} \mathrm{O} \rightarrow \mathrm{H}_{2} \mathrm{O}_{2}+2 \mathrm{H}^{+} \\
& \mathrm{H}_{2} \mathrm{O}_{2} \rightarrow \mathrm{H}_{2} \mathrm{O}+1 / 2 \mathrm{O}_{2}
\end{aligned}
$$

5.2. Path 2: Current Increase (CI), Positive Relaxation (PR), and Current Decay (CD). In our model, the CI stage is controlled by the adsorption of a species at the Nafion- $\mathrm{TiO}_{2}$ interface generated during illumination. Wang and $\mathrm{Ku}$ observed that in basic $\mathrm{pH}$, the photocurrent of a mixed bare and Nafioncoated $\mathrm{TiO}_{2}$ interface was reduced to a CI pattern. ${ }^{22}$ In previous reported results, the steady state current of path 2 was not affected by an acidic $\mathrm{pH}$ and the influence of a basic $\mathrm{pH}$ differed from a study to another, suggesting that the counterion attached to $\mathrm{OH}^{-}$ions would possibly be responsible for this variable effect. ${ }^{17,22}$

In our experiments, $\mathrm{NaOH}$ was used as a base and $\mathrm{Na}^{+}$ions are known to reduce the mobility of $\mathrm{H}^{+}$ions in the Nafion membrane, ${ }^{36}$ resulting in a lower conductivity, higher ohmic losses, and therefore lower overall current as observed in our experiments. The nature of the catalytic sites controlling the CI is explained by the PR stage. One possible explanation is that electrons are trapped in the $\mathrm{TiO}_{2}$ structure to form negative sites that would combine with $\mathrm{H}^{+}$ions in the Nafion membrane. When light is switched off, electrons and $\mathrm{H}^{+}$ions that were blocked in these sites are released and recombine at the cathode to form $\mathrm{H}_{2}$, explaining the $\mathrm{PR}$ and the ongoing but decreasing production of $\mathrm{H}_{2}$ observed in the experiments from Rongé et al. ${ }^{17}$ These adsorption mechanisms may involve the sulfonic groups of Nafion as suggested by Wang and $\mathrm{Ku}$, and again be poisoned by the presence of $\mathrm{Na}^{+}$ions in the solution. ${ }^{30}$ Following these observations, the mechanism behind path 2 would use water bound at the sulfonic groups of the Nafion to perform water splitting at the $\mathrm{Nafion}-\mathrm{TiO}_{2}$ interface. The reactivity of these groups would be reduced by the poisoning of $\mathrm{Na}^{+}$from the channel in basic conditions. Species $B$ would then be the protons generated by the electrochemical reaction at the Nafion- $\mathrm{TiO}_{2}$ interface.
Even though modeled CI and PR stages are related to formation and recombination of the same reactive sites, their time scales differ. The long adsorption time scale could result from the diffusion of water in Nafion fueling oxidation and adsorption reactions at the $\mathrm{Nafion}-\mathrm{TiO}_{2}$ interface, or from the buildup of a $\mathrm{H}^{+}$concentration gradient accross the membrane. ${ }^{17}$ The latter idea is favored since the DOE showed that $r_{2}^{*}$ is influenced by both cathodic $\mathrm{H}_{2}$ preconditioning and anodic $\mathrm{pH}$.

A mechanism involving the proton activity of both the anode and the cathode can be hypothesized: $\mathrm{H}_{2}$ would adsorb on platinum, generating a negative current as observed during the preconditioning of experiments, and therefore increasing the activity of $\mathrm{H}^{+}$ions at the cathode.

$$
\mathrm{H}_{2}+\mathrm{M} \leftrightarrows \mathrm{H}-\mathrm{M}+\mathrm{H}^{+}+e^{-}
$$

The generated activity gradient, enhanced by a basic anodic $\mathrm{pH}$, would refrain $\mathrm{H}^{+}$ions to diffuse to the cathode and favor instead their adsorption on negatively charged electrongenerated sites at the Nafion- $\mathrm{TiO}_{2}$ interface. When light is switched off, these sites would desorb. The produced $\mathrm{H}^{+}$ions would travel through the Nafion membrane, while produced electrons would travel through the metallic wire, generating the PR. The two species would recombine at the cathode to produce $\mathrm{H}_{2}$. This explains the ongoing $\mathrm{H}_{2}$ production that was observed by Rongé et al. when the PR was observed.

$$
2 \mathrm{H}_{\mathrm{ads}}^{+}+2 e_{\mathrm{ads}}^{-} \leftrightarrows \mathrm{H}_{2}
$$

The absence of PR or NU in neutral $\mathrm{pH}$ would result from the favored reduction of anodic $\mathrm{O}_{2}$ into water in acidic conditions by the available electrons and $\mathrm{H}^{+}$ions stored in these anodic sites, preventing its recombination with cathodic $\mathrm{H}_{2}$.

$$
\mathrm{O}_{2}+2 \mathrm{H}_{\mathrm{ads}}^{+}+2 e_{\mathrm{ads}}^{-} \rightarrow \mathrm{H}_{2} \mathrm{O}
$$

The PR was not present or faster in the sets of experiments of this work, suggesting that the PR stage is very dependent on the way the electrodes were built and particularly how Nafion was depositied on $\mathrm{TiO}_{2}$.

The DOE revealed that the CD stage could be related to an adsorption phenomenon at the anode, weakly influenced by $\mathrm{H}_{2}$ preconditioning, and therefore to path 2 . This stage could be caused by the decrease of adsorption sites at the Nafion- $\mathrm{TiO}_{2}$ interface, possibly caused by water depletion or consumption of trapped states at the Nafion- $\mathrm{TiO}_{2}$ interface. Other adsorption phenomena, such as $\mathrm{O}_{2}$ adsorption on $\mathrm{TiO}_{2}$ could be responsible for this decay. It should be noted that the decayed 
current is revived after a dark period, with a very small current loss from the previous experiment.

5.3. Negative Undershoot (NU). As explained earlier, the NU results from the reverse (fuel cell) reaction. As Figure 4 indicates, the OS and NU are symmetrical under a constant applied bias which stresses that the observed transient phenomena are dependent on the photopotential that changes over time during illumination. The same symmetry is observed in a chronoamperometric experiment of only the $\mathrm{TiO}_{2}$ photoanode in a three-electrode setup (see the Supporting Information).

\section{CONCLUSIONS}

A coupled experimental-numerical approach was used to study the physical phenomena of the transient photocurrent response of a PEC cell using a porous $\mathrm{TiO}_{2}$ photoanode, a Nafion solid electrolyte, and a dark porous $\mathrm{Pt}$ cathode. Experimental observations provided the basis for the development of the transient numerical model. Specifically, the model assumed the presence of two parallel pathways for charge transport at the photoabsorber-electrolyte interface. The model was experimentally validated and then used in combination with design of experiments to predict the transient photocurrent response of a PEC cell exposed to varying operational conditions (temperature, anode chamber $\mathrm{pH}$, cathode chamber $\mathrm{H}_{2}$ pretreatment).

The model was able to predict the transient current response utilizing parameter fitting for the various equilibrium constants and reaction rates. The sensitivity of these parameters with operational conditions was assessed using a design of experiments. The observed transient response was modeled by considering two parallel pathways for current transfer at the $\mathrm{TiO}_{2}-\mathrm{H}_{2} \mathrm{O}$ and $\mathrm{TiO}_{2}-$ Nafion interfaces. Mechanistic pathways were proposed for the two parallel current paths. One process is associated with the balance and kinetics of acidic titanol groups at the $\mathrm{TiO}_{2}-\mathrm{H}_{2} \mathrm{O}$ interface which are quickly formed at start-up and slowly recombine with the buildup of $\mathrm{O}_{2}$ concentration near the surface, generating a current shoot and a slow decrease. The second process is related to the generation of reactive sites at the $\mathrm{TiO}_{2}-$ Nafion interface with an adsorption equilibrium involving captured electrons and protons, which, upon turning off the illumination, will either desorb to form $\mathrm{H}_{2}$ at the cathode or recombine with $\mathrm{O}_{2}$ at the anode. The competition between this second pathway and the reverse electrolysis reaction, recombining anodic $\mathrm{O}_{2}$ with cathodic $\mathrm{H}_{2}$ (fuel cell reaction), explained that the relaxation of the current is either a negative undershoot, or a positive relaxation.

The coupled experimental-numerical approach used to study transient phenomena in a photoelectrochemical water splitting device allows for understanding of their origin and their subsequent exploitation for better performance and favorable process dynamics. These insights could prove to be useful in practical membrane-based PEC cells where similar semiconductor/solid-electrolyte and semiconductor-water interfaces coexist.

\section{ASSOCIATED CONTENT}

\section{S Supporting Information}

The Supporting Information is available free of charge on the ACS Publications website at DOI: 10.1021/acs.jpcc.5b12445.
Detailed experimental results of $\mathrm{H}_{2}$ preconditioning; electrochemical characterization of the $\mathrm{TiO}_{2}$ anode; scanning electron microscope images of the photoanode; development of the dimensionless model (PDF)

\section{AUTHOR INFORMATION}

\section{Corresponding Author}

*E-mail: sophia.haussener@epfl.ch. Tel.: +41 216933878.

\section{Author Contributions}

${ }^{\S}$ M.D. and T.-B. are equally contributing authors.

\section{Notes}

The authors declare no competing financial interest.

\section{ACKNOWLEDGMENTS}

The authors thank Yannick Gaudy for helpful discussions. J.R. is a fellow of the Research Foundation - Flanders (FWO). J.A.M. receives long-term structural funding from the Flemish government (Methusalem). M.D. and S.H. acknowledge the financial support of the Nano-Tera.ch initiative, as part of the SHINE project (Grant \#145936), and the Starting Grant of the Swiss National Science Foundation, as part of the SCOUTS project (Grant \#155876).

\section{REFERENCES}

(1) Rongé, J.; Bosserez, T.; Martel, D.; Nervi, C.; Boarino, L.; Taulelle, F.; Decher, G.; Bordiga, S.; Martens, J. a. Monolithic Cells for Solar Fuels. Chem. Soc. Rev. 2014, 43, 7963-7981.

(2) Haussener, S.; Xiang, C.; Spurgeon, J. M.; Ardo, S.; Lewis, N. S.; Weber, A. Z. Modeling, Simulation, and Design Criteria for Photoelectrochemical Water-Splitting Systems. Energy Environ. Sci. 2012, 5 (12), 9922.

(3) Andrade, L.; Lopes, T.; Ribeiro, H. A.; Mendes, A. Transient Phenomenological Modeling of Photoelectrochemical Cells for Water Splitting - Application to Undoped Hematite Electrodes. Int. I. Hvdrogen Energy 2011, 36 (1), 175-188.

(4) Lopes, T.; Andrade, L.; Ribeiro, H. A.; Mendes, A. Characterization of Photoelectrochemical Cells for Water Splitting by Electrochemical Impedance Spectroscopy. Int. I. Hvdrogen Energy 2010, 35 (20), 11601-11608.

(5) Le Formal, F.; Pendlebury, S. R.; Cornuz, M.; Tilley, S. D.; Grätzel, M.; Durrant, J. R. Back Electron-Hole Recombination in Hematite Photoanodes for Water Splitting. I. Am. Chem. Soc. 2014, $136,2564-2574$.

(6) Zawadzki, P.; Laursen, A. B.; Jacobsen, K. W.; Dahl, S.; Rossmeisl, J. Oxidative Trends of $\mathrm{TiO} 2$ - hole Trapping at Anatase and Rutile Surfaces. Energy Environ. Sci. 2012, 5, 9866-9869.

(7) Van de Krol, R.; Grätzel, M. Photoelectrochemical Hvdrogen Production: Springer: New York, 2012.

(8) Diebold, U. The Surface Science of Titanium Dioxide. Surf. Sci. Rep. 2003, 48 (5-8), 53-229.

(9) Imanishi, a; Okamura, K. T.; Ohashi, N.; Nakamura, R.; Nakato, Y. Mechanism of Water Photooxidation Reaction at Atomically Flat $\mathrm{TiO}_{2}$ (rutile) (110) and (100) surfaces: dependence on solution $\mathrm{pH} . \mathrm{I}$. Am. Chem. Soc. 2007, 129 (110), 11569.

(10) Fujishima, A.; Zhang, X.; Tryk, D. A. TiO2 Photocatalysis and Related Surface Phenomena. Surf. Sci. Rep. 2008, 63, 515-582.

(11) Peter, L. Kinetics and Mechanisms of Light-Driven Reactions at Semiconductor Electrodes: Principles and Techniques. In Photoelectrochemical Water Splitting: Materials, Processes and Architectures; Peter, L., Lewerenz, H.-J., Eds.; RSC Publishing: Cambridge, UK, 2013; pp 19-51.

(12) Wenger, S.; Schmid, M.; Rothenberger, G.; Gentsch, A.; Grätzel, M.; Schumacher, J. O. Coupled Optical and Electronic Modeling of Dye-Sensitized Solar Cells for Steady-State Parameter Extraction. I. Phvs. Chem. C 2011, 115 (20), 10218-10229. 
(13) Walker, A. B.; Peter, L. M.; Martínez, D.; Lobato, K. Transient Photocurrents in Dye-Sensitized Nanocrystalline Solar Cells. Chimia 2007, 61 (12), 792-795.

(14) Bailes, M.; Cameron, P. J.; Lobato, K.; Peter, L. M. Determination of the Density and Energetic Distribution of Electron Traps in Dye-Sensitized Nanocrystalline Solar Cells. L.Phvs. Chem. B 2005, 109 (32), 15429-15435.

(15) Barnes, P. R. F.; Anderson, A. Y.; Durrant, J. R.; O’Regan, B. C. Simulation and Measurement of Complete Dye Sensitised Solar Cells: Including the Influence of Trapping, Electrolyte, Oxidised Dyes and Light Intensity on Steady State and Transient Device Behaviour. Phys. Chem. Chem. Phvs. 2011, 13 (13), 5798-5816.

(16) Anthony Byrne, J.; Eggins, B. R.; Dunlop, P. S. M.; LinquetteMailley, S. The Effect of Hole Acceptors on the Photocurrent Response of Particulate TiO2 Anodes $\dagger$. Analyst 1998, 123, 20072012.

(17) Rongé, J.; Nijs, D.; Kerkhofs, S.; Masschaele, K.; Martens, J. Chronoamperometric Study of Membrane Electrode Assembly Operation in Continuous Flow Photoelectrochemical Water Splitting. Phvs. Chem. Chem. Phvs. 2013, 15 (23), 9315-9325.

(18) Shimpalee, S.; Lee, W. K.; Van Zee, J. W.; Naseri-Neshat, H. Predicting the Transient Response of a Serpentine Flow-Field PEMFC. II: Normal to Minimal Fuel and Air. I. Power Sources 2006, 156 (2), 369-374.

(19) Krewer, U.; Sundmacher, K. Transfer Function Analysis of the Dynamic Behaviour of DMFCs: Response to Step Changes in Cell Current. I. Power Sources 2006, 154 (1), 153-170.

(20) Weydahl, H.; Møller-Holst, S.; Hagen, G.; Børresen, B. Transient Response of a Proton Exchange Membrane Fuel Cell. I. Power Sources 2007, 171 (2), 321-330.

(21) Zhang, S.; Jia, L.; Yu, T. Analysis of Photocurrent Responses of Oxide Films Formed on Stainless Steel. Electrochim. Acta 2013, 89, 253-261.

(22) Wang, W. Y.; Ku, Y. Effect of Solution pH on the Adsorption and Photocatalytic Reaction Behaviors of Dyes Using $\mathrm{TiO} 2$ and Nafion-Coated TiO2. Colloids Surf. A 2007, 302 (1-3), 261-268.

(23) Hoffmann, M. R.; Martin, S. T.; Choi, W.; Bahnemann, D. W. Environmental Applications of Semiconductor Photocatalysis. Chem. Rev. 1995, 95 (1), 69-96.

(24) Will, F. G. Hydrogen Adsorption on Platinum Single Crystal Electrodes. I. Electrochem. Soc. 1965, 112 (4), 451.

(25) Santos, E.; Hindelang, P.; Quaino, P.; Schmickler, W. A Model for the Heyrovsky Reaction as the Second Step in Hydrogen Evolution. Phvs. Chem. Chem. Phvs. 2011, 13, 6992-7000.

(26) Wahl, A.; Augustynski, J. Charge Carrier Transport in Nanostructured Anatase TiO2 Films Assisted by the Self-Doping of Nanoparticles. I. Phvs. Chem. B 1998, 102 (40), 7820-7828.

(27) Bendert, J. C.; Papadias, D. D.; Myers, D. J. The Effect of Na+ Impurities on the Conductivity and Water Uptake of Nafion 115 Polymer Electrolyte Fuel Cell Membranes. I. Electrochem. Soc. 2010, $157, \mathrm{~B} 1486$.

(28) Bosserez, T.; Rongé, J.; Van Humbeeck, J.; Haussener, S.; Martens, J. Design of Compact Photoelectrochemical Cells for Water Splitting. Oil Gas Sci. Technol. 2015, 70, 877-889.

(29) Kavan, L.; Tétreault, N.; Moehl, T.; Grätzel, M. Electrochemical Characterization of $\mathrm{TiO} 2$ Blocking Layers for Dye-Sensitized Solar Cells. I. Phvs. Chem. C 2014, 118, 16408-16418.

(30) Wang, W. Y.; Yang, M. L.; Ku, Y. Photoelectrocatalytic Decomposition of Dye in Aqueous Solution Using Nafion as an Electrolyte. Chem. Eng. I. 2010, 165 (1), 273-280.

(31) Langmuir, I. The Adsorption of Gases on Plane Surfaces of Glass, Mica and Platinum. I. Am. Chem. Soc. 1918, 40 (9), 1361-1403.

(32) Mora-sero, I.; Bisquert, J. Fermi Level of Surface States in TiO2 Nanoparticles. Nano Lett. 2003, 3 (7), 945-949.

(33) Bertoluzzi, L.; Bisquert, J. Equivalent Circuit of Electrons and Holes in Thin Semiconductor Films for Photoelectrochemical Water Splitting Applications. I. Phys. Chem. Lett. 2012, 3 (17), 2517-2522.
(34) Modestino, M. a.; Dumortier, M.; Hosseini Hashemi, S. M.; Haussener, S.; Moser, C.; Psaltis, D. Vapor-Fed Microfluidic Hydrogen Generator. Lab Chip 2015, 15, 2287-2296.

(35) Kormann, C.; Bahnemann, D. W.; Hoffmann, M. R. Photolysis of Chloroform and Other Organic Molecules in Aqueous TiO2 Suspensions. Environ. Sci. Technol. 1991, 25 (25), 494-500.

(36) Okada, T.; Møller-Holst, S.; Gorseth, O.; Kjelstrup, S. Transport and Equilibrium Properties of Nafion Membranes with $\mathrm{H}^{+}$and $\mathrm{Na}^{+}$ Ions. Electroanal. Chem. 1998, 442, 137-145. 


\section{Electronic Supplementary Information}

\section{Combined Experimental-Numerical Analysis of Transient Phenomena in a Photoelectrochemical Water Splitting Cell}

Mikael Dumortier ${ }^{1}$, Tom Bosserez ${ }^{2}$, Jan Rongé ${ }^{2}$,Johan A. Martens ${ }^{2}$, Sophia Haussener ${ }^{1, *}$

${ }^{1}$ Laboratory of Renewable Energy Science and Engineering, EPFL, Station 9, 1015 Lausanne, Switzerland

${ }^{2}$ KU Leuven, Centre for Surface Chemistry and Catalysis, Kasteelpark Arenberg 23, Leuven B3001, Belgium.

\section{1. $\mathrm{H}_{2}$ preconditioning experiments}

Figure S1 shows the current profile of hydrogen preconditioning of the cathode compartment (Run 5 - Table 1). The sudden decrease in steady state current indicates hydrogen reaching the cathode and spontaneous dissociation onto the Pt surface according to the fuel cell reaction. When the current reaches a minimum, the hydrogen flow is switched off and the cathode compartment is again flushed with nitrogen. The cell is then left to equilibrate until a steady state is reached, presumably leaving the cathode surface fully hydrogenated.

This approach was chosen as illuminating the cell during the fuel cell reaction not always resulted in the typical photocurrent profile as the back reaction was too strong.

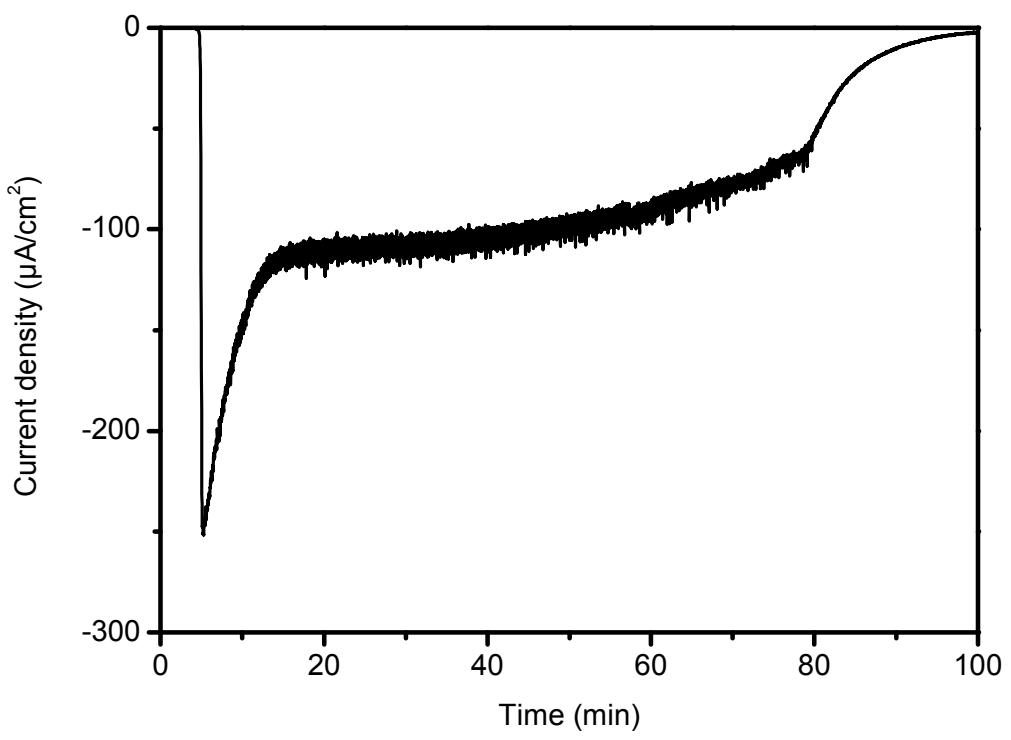

Figure S1. Preconditioning of cathode compartment with stream of pure $\mathrm{H}_{2}$ (Run 5).

\footnotetext{
* Corresponding author. E-mail address: sophia.haussener@epfl.ch, tel.: +41 216933878.
} 
Figures S2-S4 show the current profiles when illuminating the PEC cell during the fuel cell reaction in different runs (equilibrium was not yet reached). In run 6 (Figure S2), illumination was able to counter the fuel cell reaction and an anodic current was observed with a strong shoot followed by a strong CI which remained until illumination was turned off. A similar transient response is seen in run 2 (Figure S3).

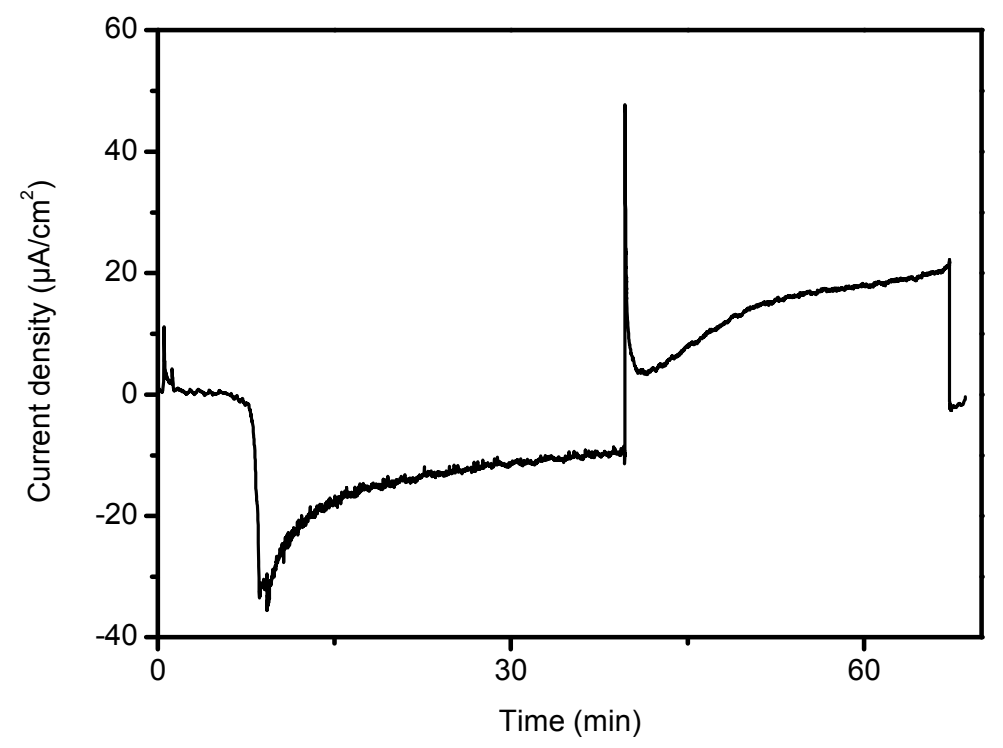

Figure S2. Preconditioning of cathode compartment with stream of pure $\mathrm{H}_{2}$ in condition 6 .

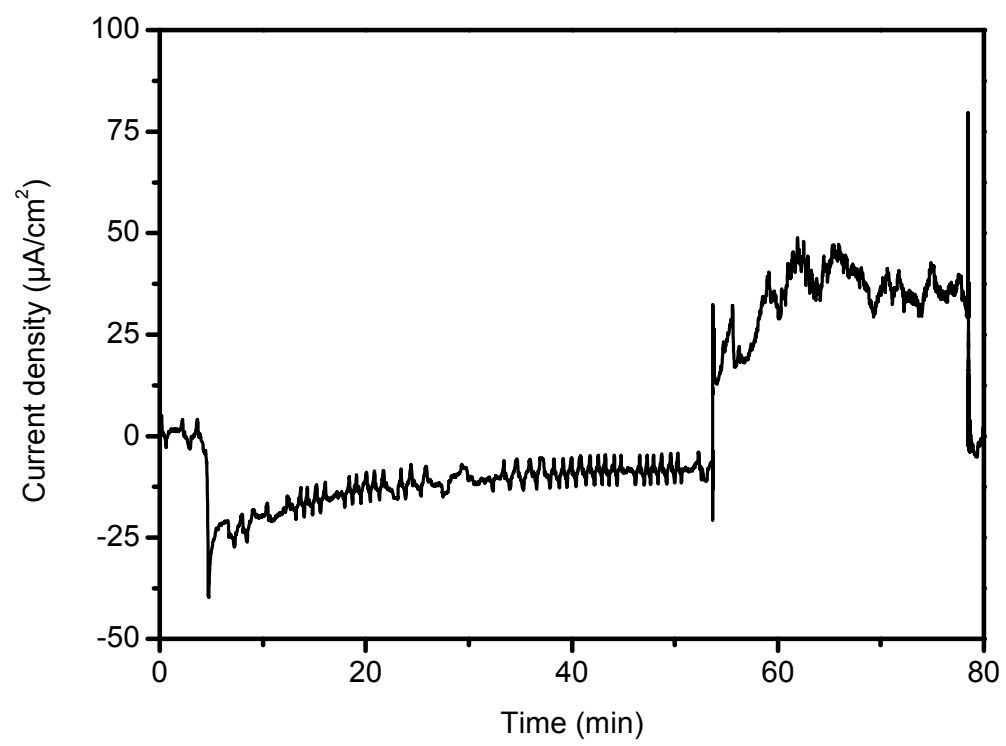

Figure S3. Preconditioning of cathode compartment with stream of pure $\mathrm{H}_{2}$ in run 2 .

However in run 5 (Figure S4), no positive current was observed when illuminating during the fuel cell reaction and even a negative shoot occurred. This effect is counterintuitive as basic conditions at the anode, while cathode conditions remain the same, should result in an additional 
Nernstian bias for the water oxidation reaction and thus a more positive anodic current. Possibly the high conductivity of the electrolyte causes a fast discharge of the cathode through trap states at the $\mathrm{TiO}_{2}$ surface.

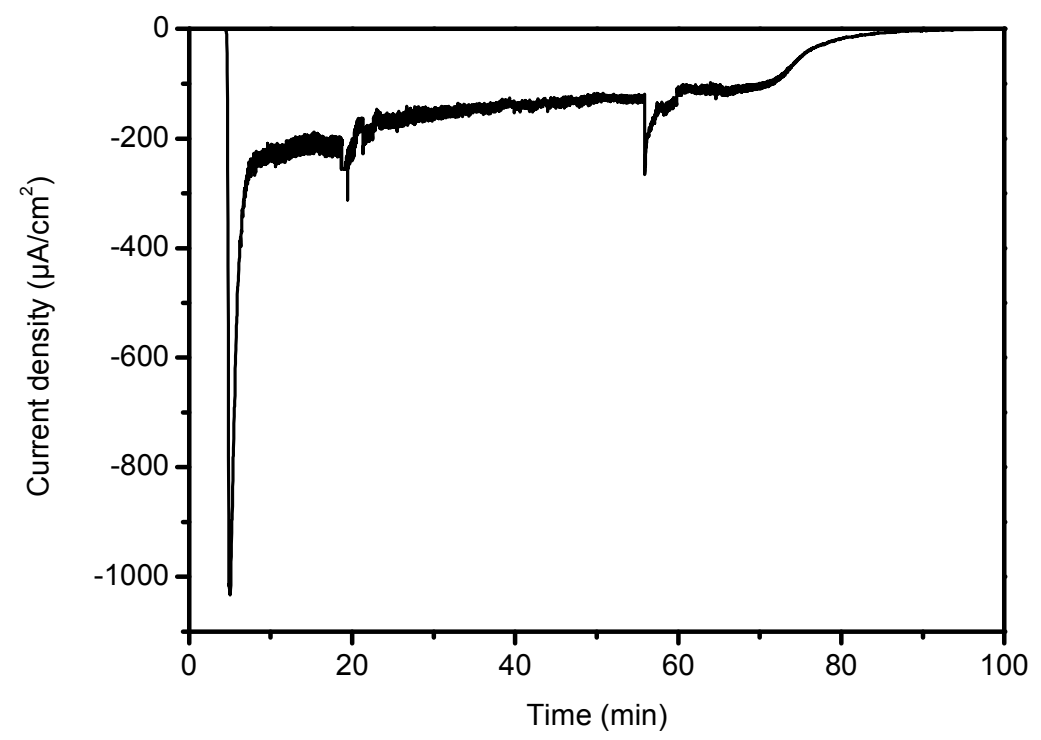

Figure S4. Preconditioning of cathode compartment with stream of pure $\mathrm{H}_{2}$ in run 5 .

\section{Electrochemical characterization of the $\mathrm{TiO}_{2}$ anode}

Figure $\mathrm{S} 5$ shows a chronoamperometric curve of a $\mathrm{TiO}_{2}$ anode $v$ s. a Pt cathode similar to the anode and cathode present in the MEA. A constant potential of $1.5 \mathrm{~V}$ vs $\mathrm{Ag} / \mathrm{AgCl}(3 \mathrm{M} \mathrm{KCl})$ was applied in dark conditions. A symmetrical OS and NU can be observed while no CI is present.

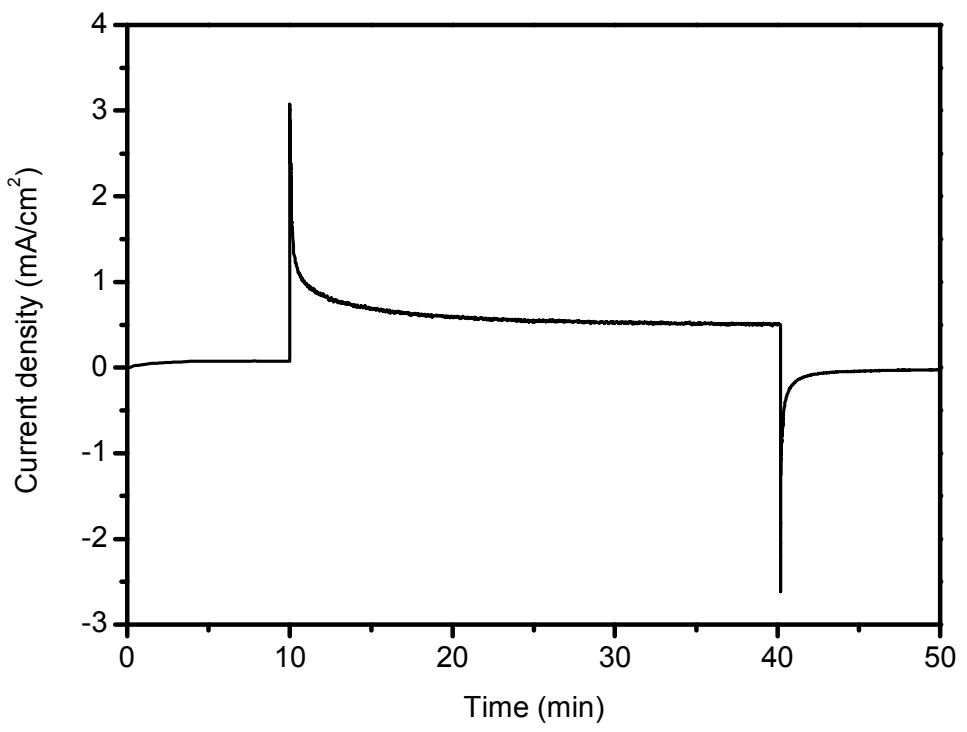

Figure S5. Chronoamperometric curve of $\mathrm{TiO}_{2}$ anode in $0.5 \mathrm{M} \mathrm{H}_{2} \mathrm{SO}_{4}$ at $1.5 \mathrm{~V}$ vs. $\mathrm{Ag} / \mathrm{AgCl}$. 


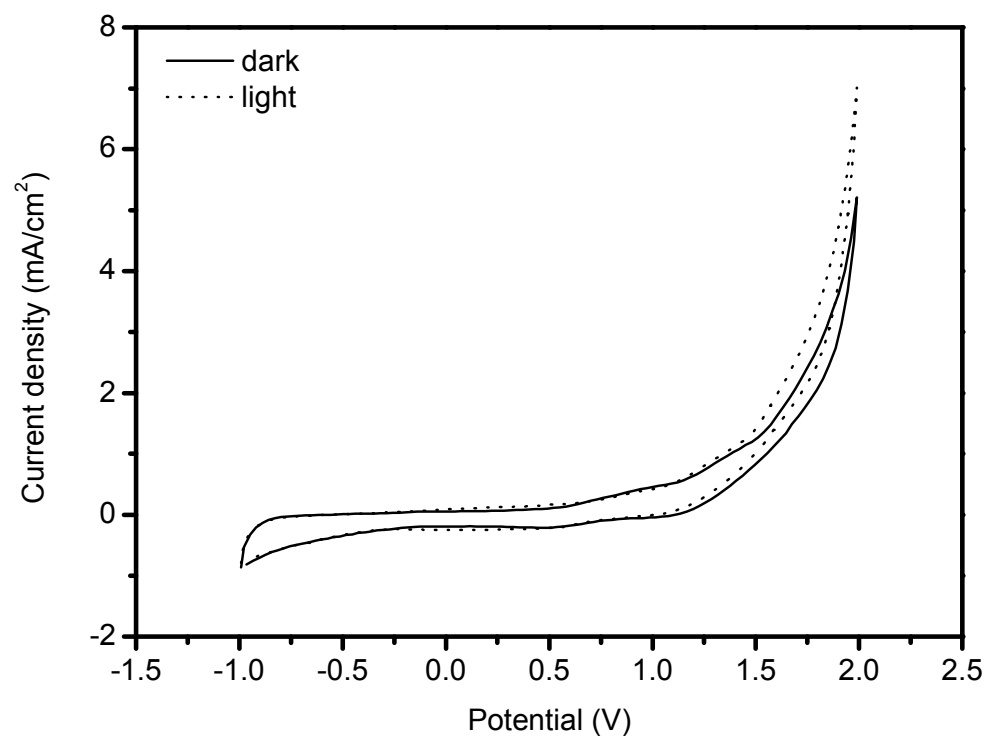

Figure S6. Cyclic voltammogram of an MEA inside the PEC cell (run 8) in dark (solid line) and under illumination (dotted line). Sweep rate was $50 \mathrm{mV} \cdot \mathrm{s}^{-1}$.

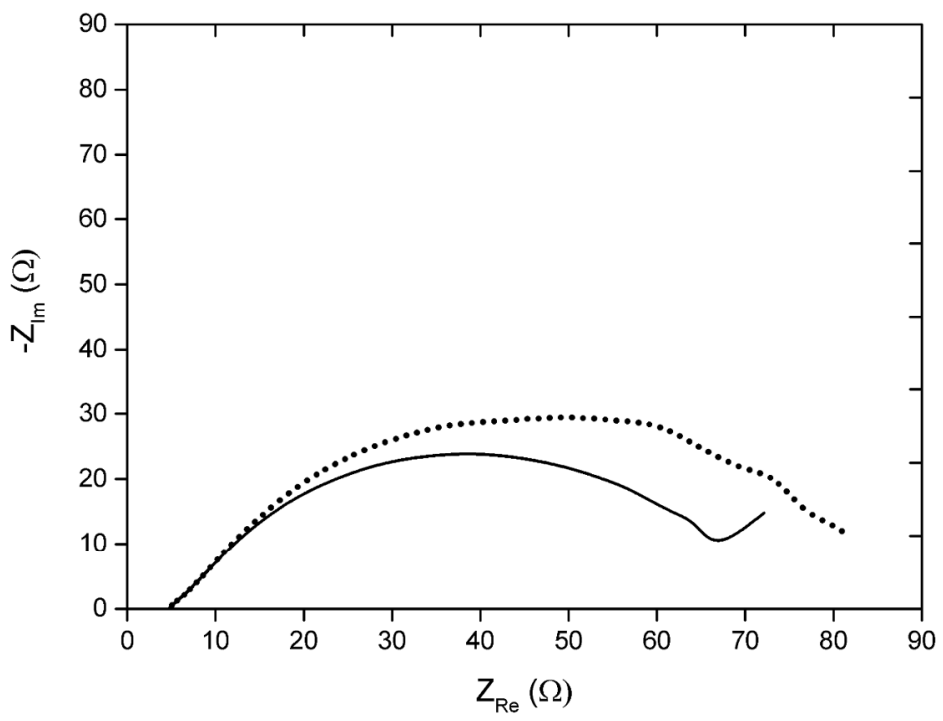

Figure S7. Nyquist impedance diagram of the cell in dark operation (dotted line) and under illumination (solid line) at an applied bias of $2 \mathrm{~V}$. 


\section{Scanning electron microscope images of the photoanode}
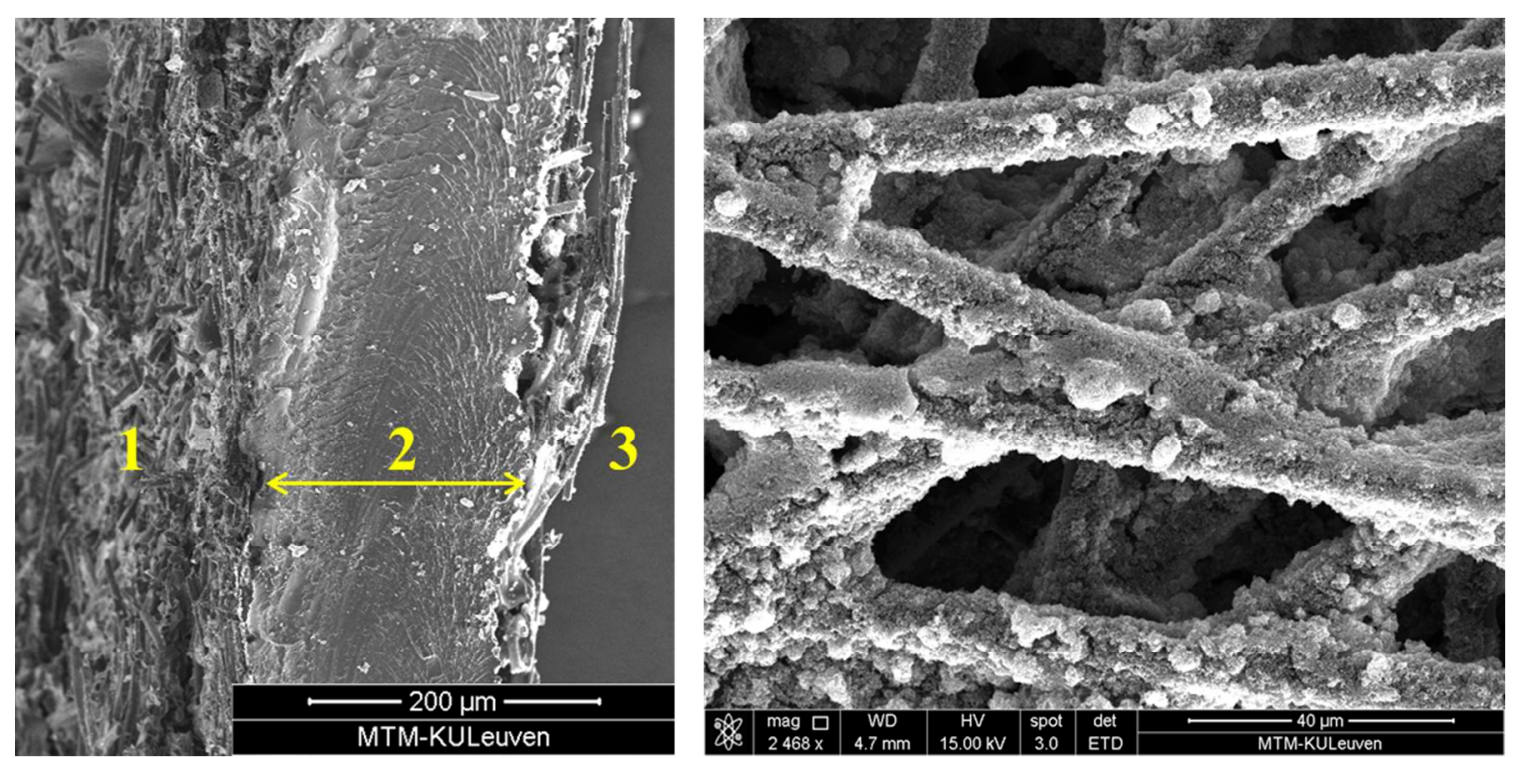

Figure S8. (left) Cross section of membrane electrode assembly (MEA): 1) photoanode; 2) Nafion $^{\circledR}$ membrane with a thickness of about $\left.180 \mu \mathrm{m} ; 3\right)$ dark cathode consisting of $\mathrm{Pt} / \mathrm{CB}$ particles on carbon fibre substrate. (right) Top view of photoanode consisting of $\mathrm{TiO}_{2}$ nanoparticles on carbon fibre substrate.

\section{Dimensionless model}

The parameters and variables of the equation system were divided by the characteristic reaction rate $r_{0}$ to extract characteristic times and constants of the system. The following dimensionless variables were used:

- Evolution times of species in the channel (in min):

$$
\tau_{A}=c_{A} / r_{0}, \tau_{B}=c_{B} / r_{0}, \tau_{O}=c_{\mathrm{O}_{2}}^{\mathrm{a}} / r_{0}, \tau_{H}=c_{\mathrm{H}_{2}}^{\mathrm{c}} / r_{0}
$$

- Characteristic adsorption times (in min):

$$
\tau_{\mathrm{ads}, A}=\left(K_{A} r_{0}\right)^{-1}, \tau_{\mathrm{ads}, B}=\left(K_{B} r_{0}\right)^{-1}
$$

- Dimensionless rate constants:

$$
r_{1}^{*}=k_{1} / r_{0}, r_{2}^{*}=k_{2} / r_{0}, r_{\text {rec }}^{*}=r_{\text {rec }} / r_{0}, r_{\text {rec }, \mathrm{l}}^{*}=k_{\text {rec }, \mathrm{l}} / r_{0}^{1 / 4}, r_{\text {rec }, \mathrm{l}}^{*}=k_{\text {rec }, \mathrm{d}} / r_{0}^{1 / 4}
$$

- Dimensionless reaction rates:

$$
r_{A}^{*}=r_{A} / r_{0}, r_{B}^{*}=r_{B} / r_{0}, r^{*}=r / r_{0}
$$

The equation system presented in the main paper from (eqs. (1) to (7)) was non-dimensionalized using these dimensionless variables:

Fraction of states filled:

$$
n_{A}=\frac{\tau_{A} / \tau_{\mathrm{ads}, A}}{1+\tau_{A} / \tau_{\mathrm{ads}, A}}
$$


$n_{B}=\frac{\tau_{B} / \tau_{\mathrm{ads}, B}}{1+\tau_{B} / \tau_{\mathrm{ads}, B}}$

Evolution of species concentration in the channels:

$\frac{d \tau_{A}}{d t}=\eta_{A}\left(r_{A}^{*}+r_{B}^{*}\right)-k_{A}\left(\tau_{A}-\tau_{A_{\text {in }}}\right)$,

$\frac{d \tau_{B}}{d t}=\eta_{B}\left(r_{A}^{*}+r_{B}^{*}\right)-k_{B}\left(\tau_{B}-\tau_{B_{i n}}\right)$,

$\frac{d \tau_{\mathrm{O}}}{d t}=\eta_{\mathrm{O}} r^{*}-k_{\mathrm{O}}\left(\tau_{\mathrm{O}}-\tau_{\mathrm{O}_{\text {in }}}\right)$,

$\frac{d \tau_{\mathrm{H}}}{d t}=\eta_{\mathrm{H}} r^{*}-k_{H}\left(\tau_{\mathrm{H}}-\tau_{\mathrm{H}_{i n}}\right)$,

Reaction rates:

$r_{A}^{*}=\phi r_{1}^{*}\left(1-n_{A}\right)$,

$r_{B}^{*}=\phi r_{2}^{*} n_{B}$,

$r_{\text {rec }}^{*}=\left[\phi r_{\text {rec }, 1}^{*}+(1-\phi) r_{\text {rec,l }}^{*}\right] \tau_{\mathrm{O}}{ }^{1 / 4} \tau_{\mathrm{H}}{ }^{1 / 2}$,

$r^{*}=r_{A}^{*}+r_{B}^{*}-r_{\text {rec }}^{*}=i_{\mathrm{ph}} / i_{0}$,

The fitting of this model to the experimental results was performed without numerical resolution, therefore the condition $r_{A}^{*}+r_{B}^{*}=1$ was imposed in equations (ii.a) and (ii.b) and $r^{*}=1$ in equations (ii.c) and (ii.d). 